\title{
COAL LIQUEFACTION PROCESS STREAMS CHARACTERIZATION AND EVALUATION
}

Gold Tube Carbonization and Reflectance Mlcroscopy

Toplcal Report

By

Gareth Mitchell

Alan Davis

December 1991

Work Performed Under Contract No. AC22-89PC89883

For

U.S. Department of Energy

Pittsburgh Energy Technology Center

Plttsburgh, Pennsylvanla

and

Consolldation Coal Company

Library, Pennsylvania

By

The Pennsylvanla State University

University Park, Pennsylvania 


\section{DISCLAIMER}

This report was prepared as an account of work sponsored by an agency of the United States Government. Neither the United States Government nor any agency thereof, nor any of their employees, makes any warranty, express or implied, or assumes any legal liability or responsibility for the accuracy, completeness, or usefulness of any information, apparatus, product, or process disclosed, or represents that its use would not infringe privately owned rights. Reference herein to any specific commercial product, process, or service by trade name, trademark, manufacturer, or otherwise does not necessarily constitute or imply its endorsement, recommendation, or favoring by the United States Government or any agency thereof. The views and opinions of authors ex. pressed herein do not necessarily state or reflect those of the United States Government or any agency thereof.

This report has been reproduced directly from the best available copy.

Available to DOE and DOE contractors from the Office of Scientific and Technical Information, P.O. Box 62, Oak Ridge; TN 37831; prices available from (615)576-8401, FTS 626-8401.

A vailable to the public from the National Technical Information Service, U. S. Department of Commerce, 5285 Port Royal Rd., Springfield, VA 22161. 
Coal Llquefaction Process Streams Characterization And Evaluation

\section{Gold Tube Carbonization}

And Reflectance Microscopy

Topical Report

Prepared by:

Energy and Fuels Research Center The Pennsylvania State University University Park, PA 16802

Gareth Mitchell Alan Davis

Prepared for:

Consolidation Coal Cornpany Research and Development 4000 Brownsville Road Library, PA 15129

F. P. Burke

R. A. Winschel

S. D. Brandes

December 1991

Under Contract to:

United States Department of Energy Under Contract No. DE-AC22-89PC89883

U.S. DOE Patent Clearance was provided by Chicago Operations Office on December 5, 1991 


\section{PROJECT ASSESSMENT}

\section{Introduction}

Under subcontract to Consolidation Coal Co. (U.S. DOE Contract No. DE-AC22-89PC89883), researchers at the Energy and Fuels Research Center of The Pennsylvania State University (Penn State) examined gold tube carbonization testing and reflectance microscopy analysis for use in support of direct coal liquefaction process development. The full report authored by the Penn State researchers is presented here. The following assessment briefly highlights the major findings of the project, and provides Consol's evaluation of the potential of the method for application to process development support. These results will be incorporated by Consol into a general overview of the application of novel analytical techniques to coal-derived materials.

\section{Summary}

This study demonstrated the use of the gold tube carbonization technique and reflectance microscopy analysis for the examination of processderived materials from direct coal liquefaction. The carbonization technique, which was applied to coal liquefaction distillation resids, yieids information on the amounts of gas plus distillate, pyridinesoluble resid, and pyridine-insoluble material formed when a coal liquid sample is heated to $450^{\circ} \mathrm{C}$ for one hour at $5000 \mathrm{psi}$ in an inert atmosphere. The pyridine"insolubles then are examined by reflectance microscopy to determine the type, amount, and optical texture of isotropic and anisotropic carbon formed upon carbonization. The gold tube carbonization technique is a potentially useful method to measure the propensity of coal liquids to unclergo retrograde (coking) reactioiss. The amount of pyridine-insoluble material formed upon carbonization of different resids was found to correspond with process conditions and feed coal characteristics. Experimental difficulties were experienced in the application of the carbonization technique to these samples; some were apparently related to problems in obtaining representative small al iquots of the heterogeneous, solids-containing samples. Other problems were attributable to the equipment used and the experimental procedures employed. 
The reflectance microscopy technique, which was applied to insoluble residues from coal liquefaction process samples, also has the potential to provide insight into the progress of conversion and retrograde reactions in the liquefaction system. It was possible to evaluate the reflectance variations of vitrinite- and process-derived residue components and determine their relationship with the rank of the feed coal, reaction temperature, and the impact of catalysts. Further development of these analytical methods as process development tools may be justified on the basis of these results.

\section{Program Description}

This report describes the work performed at the Energy and Fuels Research Center of The Pennsylvania State University under a subcontract to Consolidation Coal Co., Research and Development. Consol's prime contract to the U.S. Department of Energy (Contract No. DE-AC2289PC89883, "Coal Liquefaction Process Streams Characterization and Evaluation") established a program for the analysis of direct coal liquefaction materials. The program involves a number of participating organizations whose analytical expertise is being applied to these materials. This Participants Program has two main objectives. The broad objective is to improve our understanding of fundamental coal liquefaction chemistry to facilitate process improvement and new process development. The specific approach to achieving this objective is to provide a bridge between direct coal liquefaction process development and analytical chemistry by demonstrating the application of various advanced analytical methods to coal liquefaction materials. The methodologies (or techniques) of interest are those which are novel in their application for the support of coal liquefaction process development and those which have not been fully demonstrated in this application. Consol is providing well-documented samples from different continuous direct coal liquefaction facilities to the program participants. The participants are required to interpret their analytical data in context of the processing conditions under which the samples were generated. The analytical methodology employed then is evaluated for its usefulness in analyzing direct coal liquefaction-derived materials. 


\section{Participanic's Methodology}

Penn State applied the goid tube carbonization technique and reflectance microscopy analysis to a total of twenty-eight samples. The sample set for application of the gold tube carbonization tests consisted of eighteen coal liquefaction distillation resids $\left(850^{\circ} \mathrm{F}^{+}\right)$and two blind samples. The resids are solid at room temperature and contain THFsoluble and insoluble organics and mineral matter. THF-insoluble portions of eight distillation resids were supplied for petrographic analysis by reflectance microscopy. The 28 samples were produced at three different continuous liquefaction facilities: the Wilsonville pilot plant, the Hydrocarbon Research Inc. (HRI) bench unit, and the Lummus process development unit. The major processing parameters which varied among the Wilsonville runs were feed coal, catalyst, ash recycle, and sampling location in the plant. Samples from Wilsonville were taken from two different locations in the plant. These samples are expected to represent different extents of coal liquefaction. Some of the Wilsonville samples were composites of samples taken over long periods of single runs; others were samples obtained from a single run day. The samples from HRI also were chosen to represent material which had undergone different degrees of processing and were obtained from different plant locations. HRI samples also were chosen for a comparison of materials produced with and without the use of a thermal pretreatment of the feed coal. The Lummus samples represented ash-containing and deashed recycle streams.

The gold tube carbonization technique is a three-step procedure: the sample is carbonized, the product is extracted, and the insoluble material is evaluated petrographically by reflectance microscopy. A full description of the technique is given on pages 2 and 5-9 of the attached report.

The reflectance microscopy (petrugraphy) technique is described on pages 3 and 9-10 of the attached report. Use of this technique allows for an evaluation of the degree of condensation or hydrogenation of the resid. An increase in reflectance, upon processing, of the vitroplast contained in the sample indicates that the material has undergone condensation. 
Alternatively, a decrease in reflectance indicates that the material has undergone hydrogenation.

\section{Participant's Major Findings}

The following principal observations were reported by Penn State for the application of the gold tube carbonization technique and reflectance microscopy to coal liquefaction materials. An expanded discussion can be found in the attached report, pages 11 through 19 . The gas plus condensate values obtained in the gold tube test correlate with the total paraffinic proton content of the resids. The quality and quantity of pyridine-insoluble material produced in the carbonization test was dependent on several factors including feed coal rank, oxygen content of the resids and of the native feed coal, and sampling location in the production facility. The production of pyridine-insolubles was greater with resids produced from low-rank and weathered coals and resids taken from the first-stage reactor, especially when that reactor was operated thermally. The pyridine-insoluble carbonization residues were comprised of substantial amounts of anisotropic carbon formed through the development of mesophase. Interstage samples generated higher concentrations of mesophase spheres and mosaics than recycle samples; thus, the interstage samples appear to have a greater propensity for coking. However, high concentrations of ash and insoluble organic material in some samples interfered with the development, growth, and coalescence of mesophase.

Petrographic analyses were performed on a set of tetrahydrofuraninsoluble process samples. Various components were quantified by point counting, and reflectance values were determined for partially reacted vitrinite and high- and low-reflecting vitroplast. The processing variable which had the strongest influence on the vitroplast reflectance was reactor temperature. Higher temperatures produced higher reflectances. The comparison of interstage samples taken during operations with a low-temperature catalytic first stage with those taken during operations with a high-temperature thermal first stage showed that temperature, not degree of conversion, had the principal influence on vitroplast reflectance. The inference from this is that higher temperature promoted condensation reactions. The reflectance of partially reacted vitrinite increased in the order: feed coal < interstage sample 
$<$ recycle sample; thus, its reflectance increased with residence time in the system.

\section{Consol Evaluation}

The gold tube carbonization test has potential for application to process-derived samples. For the samples analyzed here, the reproducibility of the method was not high. However, trends clearly can be detected. This indicates that the technique has the potential for analysis of these materials and is useful for process development. This utility could be increased by improving reproducibility. The presence of IOM and ash in the samples studied was partially responsible for the poor observed reproducibility. In general, analyzing inhomogeneous materials may be problematic. It appears that reproducibility problems could be minimized by application of the technique to solids-free samples. However, dedication of this technique to solids-free samples will reduce its usefulness as a process development tool. The gold tube carbonization test is labor intensive. Sample preparation is time consuming and requires considerable skill. The carbonization experiment requires roughly three hours, including pressurization, heat up, soak time, cool down, and depressurization. Sample work-up requires approximately 48 hours for pyridine extraction of the samples plus the time necessary to examine the samples by optical microscopy. The carbonization equipment is costly (approximately $\$ 100,000$ ), Decause high pressures and temperatures are required for the reaction. The gold tubing, which is preferred for use as the mini-reactor, also is costly.

Two blind samples were provided for testing in the gold tube experiment. One sample (Reference No. 20) was correctly identified as an interstage resid produced at the Wilsonville facility. It was, in fact, the same material that was issued as sample Reference No. 8, the whole interstage resid from Wilsonville Run 257 . The second blind sample (Reference No. 19) was a duplicate of the sample issued to Penn State as sample Reference No. 9, a whole recycle resid from Wilsonville Run 259. The Penn State researchers correctly identified it as a Wilsonville recycle resid. However, they found no mineral matter in either sample and believed them to be deashed samples. This illustrates the sampling difficulties discussed earlier. In both cases, they incorrectly 
identified the blind samples as the products of a low rank feed coal. Run 257 used Ill inois No.6 coal as feed, and Run 259 used Pittsburgh seam coal as feed; both are of high-volatile bituminous rank. The incorrect identifications resulted, in part, from sampling difficulties.

The reflectance microscopy technique was shown to be potentially useful for the analysis of solid heterogeneous, process-derived samples. The method demonstrated a high degree of reproducibility in examination of the vitroplast reflectance $(0.008 \%$ mean deviation in reflectance) and somewhat poorer precision for partially reacted vitrinite $(0.032 \%)$. Some relationships can be observed between reflectance measurements and processing parameters such as reactor ter.peratures, the presence or absence of catalyst, and feed coal rank. In some cases, certain expected trends due to major process variable changes such as reactor temperature or the presence or absence of catalyst were obscured by other process variables such as residence time. A clear explanation for differences in the reflectance measurements of samples produced under diverse conditions may not be possible. The reflectance method is relatively rapid, requiring only a few minutes for examination of the sample. The equipment cost is on the order of $\$ 85,000$.

\section{Further Development}

There are a number of avenues for further development of the techniques described here. The gold tube carbonization method needs to be further refined. Experimental parameters were originally established to accommodate solvent refined coal (SRC) samples, and may not be appropriate for samples from current liquefaction processes. Problems associated with sampling heterogeneous samples need to be resolved before the method can be considered a tool for process development. This may evuwil better homogenizing the sampies mechanically or using only the soluble portion of the resids. The latter choice may cause problems in interpretation of thie results.

A relationship was observed between the amount of pyridine-insoluble material produced in the gold tube experiment and the oxygen content (rank) and weathered status of the feed coal. Additionally, the phenolic -OH content of the resid was correlated with the amount of pyridine- 
insolubles formed in the gold tube experiment. These relationships are of considerable interest. Relationships with these and other resid properties should be further explored after the precision of the method is improved.

Reflectance microscopy is well developed for inspection of coal macerals, but not for solid direct coal liquefaction process-derived materials. In the work done here, the method showed considerable potential for analysis of the THF-insoluble portion of direct coal liquefaction resids. Prior to full utilization of the method for process development, however, an expanded sample set of well-documented materials will need to be examined and evaluated so that a better understanding of the influence of process variables on the reflectance measurements can be obtained.

\section{Contractor's Statement of Mork}

Within the liquefaction process, coal-derived liquids may participate in condensation reactions and the formation of semi-coke through a mesophase mechanism. These reactions are inimical to the process and may be responsible for some operational problems, reduced reactivities toward conversion, and reduced yields of desirable products. Controlled carbonization experiments, followed by optical microscopy (for examination of the pyridine insoluble portion of the carbonization product), may be a useful empirical test for an improved understanding of these mechanisms. The gold tube carbonization test devised at Penn State is such a method. In this technique the propensity of different coal liquids to become involved in retrograde (coking) reactions can be determined. This technique has been applied to SRC-II materials and liquid chromatographic fractions of coal liquids, but not coal liquefaction prncess streams produced by current technology. As such, this technique fits within the scope of the participants program. This test yields information on the total amount of isotropic and anisotropic carbon formed, and its mosaic texture, when a coal liquid sample is heated in an inert atmosphere to $450^{\circ} \mathrm{C}$ for one hour at $5000 \mathrm{psi}$. The technique requires approximately $250 \mathrm{mg}$ of sample.

Examination of the solid organic materials resident in coal liquefaction process streams by reflectance microscopy may also provide some insight 
into the progress of conversion and retrograde reactions in the liquefaction system. A shift to higher reflectance of the vitroplast contained in the sample, relative to the feed coal vitrinite, will indicate that the material has undergone retrogressive reactions to more condensed structures, and a lower reflectance can be interpreted as evidence of hydrogenation.

Consol will supply to Penn State twenty-eight (28) samples, as designated in the attached list; twenty for gold tube carbonization tests and and optical microscopy, and eight for reflectance microscopy.

Eighteen of the twenty samples designated for gold tube carbonization experiments will be supplied to Penn State with the following information, as available: elemental analyses, ash content, ash elemental analysis, phenolic $-\mathrm{OH}$ concentration, calorific value, hydrogen classes by $1 H-N M R$, and the full history of the sample (plant, process conditions, age, and storage conditions). Two of the twenty samples for gold tube iests will be supplied to Penn state with no documentation to serve as blind controls. The twenty samples designated for gold tube carbonization tests are non-distillable residual materials which may contain insoluble organic matter (IOM) and ash. Sample size will be at least 1 g. Most samples will be brittle pitch-like materials that will be supplied as approximately minus 8 mesh $(2.4 \mathrm{~mm})$ pieces. These twenty samples will form the basis for an evaluation of the gold tube carbonization method.

Eight samples designated in the attached 1ist for reflectance microscopy are the THF insoluble portion of process stream samples. These samples contain IOM and also may contain ash. Identification of the source stream and other pertinent information will be supplied with these samples. Sample size will be at least $0.5 \mathrm{~g}$.

Penn State will perform the above noted tests and analyses. Replicate reflectance microscopy analyses will be performed as necessary to assess data quality. 
COAL LIQUEFACTION PROCESS STREAM CHARACTERIZATION AND EVALUATION

\author{
Submitted to Consolidation Coal Company \\ under
}

DOE Contract No. DE-AC22-89PC89883

November 1, 1991

by

Gareth Mitchell and Alan Davis

Energy and Fuels Research Center

The Pennsylvania State University

University Park, PA 16802 
$\underline{\text { Page }}$

EXECUTIVE SUMMARY ......................... iv

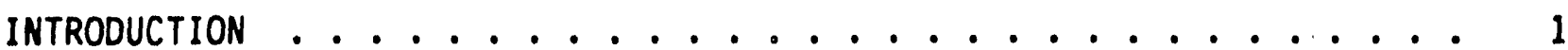

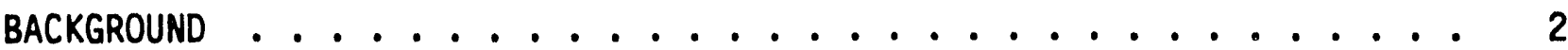

Gold-tube Carbonization .................. 2

Reflectance Analyses .................. 3 FXPERIMENTAL ............................. 4

Samples ......................... . . . 4 4

Gold-tube Carbonization Procedure . . . . . . . . . . . 5

Tube Preparation ................. 5

Carbonization ..................... 6

Sample Work-up .................. 6

Petrographic Analysis ............... 7

Reflectance Microscopy . . . . . . . . . . . . . . 9

RESULTS AND DISCUSSION ....................... 11

General Residue Microscopy . . . . . . . . . . . . 11

Gold-tube Carbonization ................. 12

Quality of Carbonization Data ........... 12

Carbonization - Liquefaction Interrelationships ...... 13

Petrography of Carbonized Products ........... 16

Reflectance Analysis ................. . 17

Blind Samples . . . . . . . . . . . . . . . 19 
TABLE OF CONTENTS (continued)

Page

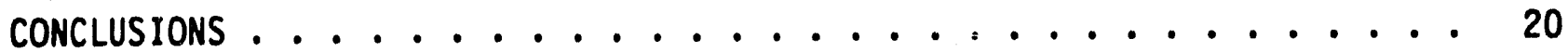

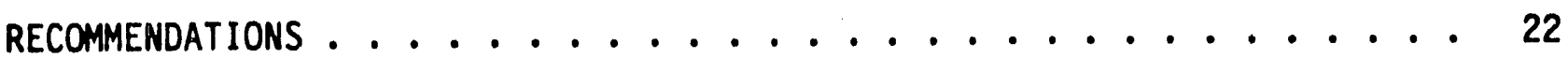

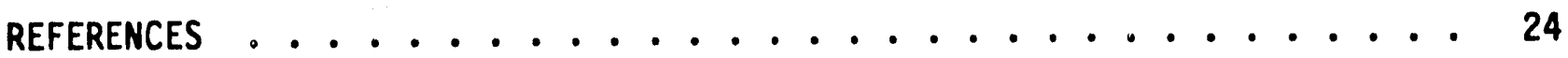




\section{EXECUTIVE SUMMARY}

Twenty-eight samples were received from Consol in December 1990. Eighteen well-characterized non-distilled resid samples were provided for the evaluation by the gold-tube carbonization technique $(\$ 1-\$ 18)$ and two additional resid samples ( $\# 19$ and $\$ 20)$ were provided for blind analysis. The remaining eight samples were provided as THF-insoluble fractions for reflectance photometric measurements on the coal- and process-derived residue materials. These samples ( $\$ 21$ - \$28) corresponded respectively to eight of the whole product resids $(\# 7-\$ 14)$ designated for gold-tube carbonization.

The gold-tube carbonization technique employed in this study utilized a $250 \mathrm{mg}$ sample of resid which was welded into gold tubing under a nitrogen atmosphere and at liquid nitrogen temperatures. The tubes were then heated to $450{ }^{\circ} \mathrm{C}$ for $1 \mathrm{~h}$ at a pressure of $5000 \mathrm{psi}$. Following the reaction, the tubes were vented and the contents Soxhlet extracted in pyridine for $48 \mathrm{~h}$. The percentages of gas $i$ condensate, pyridine- insoluble and soluble products were obtained. The pyridine insoluble fraction was prepared for optical microscopy where a point-count ana?vs is was used to determine the amount of anisotropic and isotropic carbon produced from the carbonization.

Complications associated with the gold-tube carbonization tests related to the difficulty in obtaining a representative sample, some furnace control problems, and difficulty with pyridine extraction. Most of these problems resulted from the use of extremely small samples with variable and unevenly distributed ash and insoluble organic matter (IOM). These problems in combination resulted in poor repeatability with regard to the correlation between pyridine insoluble material reported following carbonization and the ash plus IOM contained in the original sample. Nevertheless, although random variability exists in these data, it was not expected to interfere with the interpretation of major trends.

The percentage of gastcondensate was twice as high for the HRI Black Thunder resids compared to Lummus and Wilsonville resids. A correlation matrix of the data provided at least a partial explanation for this difference. It seems that as the total content of paraffinic protons $\left({ }^{2} H-N M R\right.$ alkyl beta + ganma fractions) increased, the percentage make of gas+condensate during carbonization increased. The Black Thunder resids have the largest amount of paraffinic protons. However, it was not possible to determine with certainty whether the higher paraffinic nature of these resids results from the particular coal being used or from HRI process conditions.

Production of pyridine insolubles appeared to be greatly influenced by coal rank and process conditions. Regardless of the liquefaction process, resids from the Wyodak subbituminous coal, those of the Ohio 6 runs using weathered coal, and the thermal/catalytic interstage $111 . \$ 6$ samples produced the most pyridine insolubles. Each of these coals have more associated oxygen functionality, some of which has been passed to the resid. A relationship was identified wtich showed that as the concentration of phenolic hydroxyl 
increased, so did the amount of pyridine insolubles produced during the goidtube carbonization.

Comparison of phenolic $\mathrm{OH}$ concentrations with percentage conversion of soluble resid to pyridine insolubles (pyridine insoluble values corrected for ash+IOM) showed two distinct relationships; generally one for the Wilsonville samples and the other for HRI samples (Lummus is divided among the two relationships). Both relationships show that as phenolic $\mathrm{OH}$ increases so does conversion of pyridine solubles to insolubles. Thus, for a given level of phenoiic $\mathrm{OH}$ the $\mathrm{Black}$ Thunder. HRI samples appear to produce relatively more pyridine insolubles. The Wilsonville samples form a fairly tight relationship which suggests that when phenolic $\mathrm{OH}$ content of the resids falls below 0.76 $\mathrm{meq} / \mathrm{g}$ there may be a net production of pyridine solubles during carbonization.

A rank suite of coals was provided from two-stage catalytic processing at the Wilsonville pilot plant. Samples included resids from the first-stage reactor (interstage) and recycle material that had passed through both stages. More pyridine insolubles were produced from coals of lower (subbituminous) and higher (hvAb) rank compared with two other bitumincus coals of intermediate rarik. Also, more pyridine insolubles were produced from the interstage resids compared to the recycle material. Thus, the additional catalytic processing provided by the two-stage liquefaction serves to reduce the potential of forming pyridine insolubies. This conclusion was supported by a comparison of the IIl.\#6 catalytic/catalytic and thermal/catalytic Wilsonville runs in which more pyridine-insoluble material was formed from the interstage thermal run and the least was produced from the recycle catalytic/catalytic run.

Petrographic analyses performed on all gold-tube carbonization residues (pyridine insoluble) enabled comparisons to be made of the amounts of mesophase carbon produced, and the relative size of the coristituent spheres and mosaics to be contrasted. Unfortunately, interpretation of these data were severely hampered by our inability to account for ash and IOM concentrations in the resids. It may also explain why no correlations were found between our petrographic and the chemical data provided by Consol. As the concentration of the ash and IOH increased, the size and coalescence of the mesophase decreased.

Generaily, a greater total volume percentage of mesophase (spheres and mosaics) was produced from the Wilsonville interstage samples compared to the recycle samples, suggesting that first-stage catalytic reaction generates products having a greater propensity to lead to coking problems. The I11. $\$ 6$ thermal/catalytic runs showed higher mesophase production as well. Both the 111. 6 and Wyodak coals have generated mesophase at the Wilsonville plant over the years. However, analys is of the gold-tube residues from the Wyodak runs (Lummus and Wilsonville) showed that low-reflecting vitroplast was formed in greater concentration from runs with this coal. This may explain our further observations of a significant amount of secondary vitroplast in the THFinsoluble residues from Wilsonville (Wyodak runs). 
Mean random reflectance was performed on process- and vitrinite- derived components (high-reflecting vitroplast, partially reacted vitrinite and lowreflecting vitroplast) of the THF-insoluble residues and their corresponding whole product resids. Evaluation of precision using duplicate analyses showed that vitroplast reflectance could be repeated within an average of $0.008 \%$, whereas that of partially reacted vitrinite had a repeatability of $0.032 \%$. Results of the analyses show that high-reflecting vitroplast reflectance values for the interstage catalytic/catalytic samples are lower or equal to those of the recycle. This trend was reversed for the thermal/catalytic (II1.\#6) runs. Comparing high-reflecting vitroplast reflectance values with the first-stage reaction temperature revealed that initial stage reaction temperature could be maintained at lower levels in the presence of catalyst to achieve the same level of conversion without introducing significant molecular condensation.

Reflectance values for partially reacted vitrinite are higher than those of the feed coals and are higher for the recycle compared with the interstage samples. This may be directly related to the increased residence time in the system for the recycle samples. The Wyodak runs produced a considerable amount of partialiy reacted vitrinite (huminite), a result which was not unexpected. However, the presence of high-reflecting vitroplast in relatively high concentration was surprising and suggests that the material may be derived from the product fraction.

Partially reacted vitrinite and low-reflecting vitroplast also were observed in fairly large amounts $(13-20 \%$ and $16-18 \%$ volume percent, respectively) in the thermal/catalytic 111 . $\$ 6$ recycle sample. Point count analyses of the residues revealed that on a whole-residue basis, the two components were found in about $1.0 \%$ concentration by volume. This concentration, although relatively low, may suggest that space rate was perhaps too high during the thermal/catalytic recycle run. This could cause incomplete thermal rupture of coal particles and incomplete hydrogenation of preasphaltenes (low-reflecting vitroplast).

Our general assessment of the application of the two analytical procedures presented in this report to liquefaction process control can be summarized as follows. The gold-tube carbonization technique, al though difficult to perform, has some potential for correlating process and coal parameters with resid chemistry (quality). Also, the test can provide a means of evaluating the potential of coals and/or process conditions to produce pyridine insolubles and provide information on whether mesophase-derived carbon may be a probiem during processing. Reflectance variations of vitrinite- and process- derived residue components shows some relationship with the rank of the original feed coal, with reaction temperature and the presence or absence of catalysts. 
Further, some specific recommendation have been offered to improve the precision of the gold-tube carbonization test. These include performing the test on samples which are free of ash and IOM, samples should be properly homogenized before analys is to eliminate subsampling problems, a greater sample weight should be employed, and alundum thimbles should be used during Soxhlet extraction. 


\section{INTRODUCTION}

This work was initiated to evaluate both gold-tube carbonization and reflectance residue microscopy as potential empirical tests that could help bridge the gap between the development of direct liquefaction processes and analytical chemistry. These techniques were developed and have been used for the assessment of the severity of process conditions (1), generation of newly formed organic and inorganic solids as a result of coal or process conditions (2), and the propensity for specific coal-liquids fractions to become involved in retrograde (coking) reactions $(3,4)$. However, they have not been fully tested on well-documented process materials nur fully exploited for their potential to provide improved understanding of current liquefaction process technology.

During coal hydroprocessing, coal-derived liquids may become involved in condensation reactions that result in the formation of semi-coke through the formation of mesophase. Liquid products derived from coals of different rank may respond differently to given reaction conditions just as the coals themselves may respond differently and give variable total conversion and product yields. From past gold-tube carbonization work (4), we have found that different molecular weight and functional-group fractions of coal-derived liquids (SRC) tend to produce variable amounts and kinds of structured carbons during relatively low-temperature, high-pressure carbonization. f.lso, it has been demonstrated that liquefaction process time profoundly influences the amount and type of structured carbons formed from carbonization of solventrefined coal products (4).

Characterization by reflectance microscopy of solid organic materials specifically derived from reactive coal macerals may also provide some insight into the progress of conversion or retrogressive reactions diring liquefaction. Typically, an increase in the reflectance of vitrinite and vitrinite-derived residue components signifies that the material has undergone retrogressive reactions to yield more condensed structures (5). Lower reflectance values suggest that hydrogenation may have occurred but has resulted in incomplete conversion to liquid hydrogenated products.

To evaluate these techniques, Consolidation Coal Company through a contract with DOE has provided twenty-eight samples from three major bench or pilot liquefaction processes. Samples have been selected from a wide range of feed coals and process conditions. Twenty of these samples have been identified for gold-tube carbonization, whereas the remaining eight have been provided for the evaluation of reflectance microscopy. This report discusses the findings from the analytical investigation. 
BACKGROUND

Gold-tube Carbonization

With regard to liquefaction, the gold-tube carbonization technique was originally developed to assess the propensity of SRC's and SRC fractions (from sequential elution solvent chromatography [SESC]) to undergo retrogressive reactions forming insoluble carbonaceous solids and the dependency of these reactions on process conditions such as time, temperature and pressure (3). The technique was designed to heat about $250 \mathrm{mg}$ of coal product sealed in gold tubing for varying times to iemperatures up to $600^{\circ} \mathrm{C}$ at elevated pressures in an inert atmosphere. Gold tubing was selected as an inert containment vessel to eliminate the possibility of catalys is during carbonization. Following carbonization, the contents of the gold tube were extracted in pyridine to determine the amount of semi-coke formed during the test. These data were corrected for the concentration of pyridine insolubles in the precursor. The pyridine-insoluble residues were then examined by optical microscopy to determine the types of carbonaceous solids formed during the reaction (anisotropic mesophase or isotropic material).

Figure 1 shows the soak-time/temperature relationship for the formation of pyridine insolubles developed from the gold-tube carbonization of an Ili inois \#6 short-contact time SRC (3). This kinetic study was undertaken to establish a standard set of conditions from which a large number of coal liquids and coal-liquid fractions could be evaluated. The standard conditions selected from this study were $450{ }^{\circ} \mathrm{C}$ for $1 \mathrm{~h}$ soak time under 5000 psi pressure in a nitrogen atmosphere.

Results of work on SRC and SRC fractions using the standard conditions have been described elsewhere $(4,6)$. Briefly, the technique was used to improve upon the use of pyridine solubility to estimate the proportion of semicoke formed during the runs. The residues of such extractions may not be composed wholly of anisotropic semi-coke, but may also contain isotropic material in varying amounts, and of sufficiently high molecular weight to render it insoluble in the solvent. In these experiments the proportion of anisotropic semi-coke in the residues was found to increase with the amount of pyridine insolubles. The sizes of mosaics formed during gold-tube carbonization of a long-contact SRC were found to be greater than those obtained from a short-contact SRC; this was attributed to enhanced fluidity and molecular mobility resulting from a lower functionality. Confirmatory results were obtained from the examination of the gold-tube carbonization residues of specific fractions of SRCs prepared by SESC. The fractions with the most highly functional components had the greatest tendency to form coke, and the coke derived from these fractions had smaller mosaic sizes than those derived from the more aromatic fractions. 


\section{Reflectance Analyses}

Reflectance photometric analyses have been used fairly extensively for the evaluation of the hydrogenation of different rank coals in single $\left(425^{\circ} \mathrm{C}\right.$, $\left.5000 \mathrm{psi} \mathrm{H}_{2}, 30 \mathrm{~min}\right)$ and two-stage $\left(275^{\circ} \mathrm{C}, 30 \mathrm{~min}\right.$ then $425^{\circ} \mathrm{C}, 30 \mathrm{~min}$ at 5000 psi $\mathrm{H}_{2}$ ) liquefaction in the absence of solvent (7). These studies compared the influence of the presence and absence of molybdenum catalysts, not only to conversion of coal to solvent-soluble products, but also to changes in the reflectance of the insoluble residue materials. Because the maximum reaction temperature was the same during all tests $\left(425^{\circ} \mathrm{C}\right)$, the differing reflectance values could be attributed to difference in the starting materials, i.e. the coals. The results of this investigation showed that at the same reaction temperature coals of different rank reacted differently to process conditions. For lignite and subbituminous coals, temperature-staged (non-catalytic) residues were of higher reflectance than those of the single-stage reaction. For coals of high volatile $C$ and $A$ bituminous rank this effect was reversed. Since higher reflectance may be an indication of a greater degree of molecular condensation, these data suggest that lower rank coals have a greater tendency to develop crosslinks under temperature-staged conditions. Consequently, higher rank coals may show lower degrees of molecular condensation under the same conditions.

When a molybdenum catalyst (sulfided ammonium molybdate) was employed in the same experimental design, not only were conversion and product yields higher, but reflectance values obtained on the vitrinite-derived THF-insoluble residues were significantly higher than those of non-catalytic runs. As a consequence of the doubling of conversion in the presence of a catalyst, the remaining solvent-insoluble materials were found to be of higher reflectance and presumably more highly condensed than those of the non-catalytic condition.

Because microscopic studies of the solvent-insoluble fractions provide only indirect information regarding the production of liquids, some studies were undertaken in which the reflectance distributions of the insoluble residues were compared with those of the whole unextracted products (5). Such an approach is only possible where a process solvent is not employed in "dry" liquefaction experiments. The results of this work clearly showed how the use of a catalyst in such experiments generated significant amounts of lowreflecting vitroplast. In contrast, the thermal runs produced mostly highreflecting vitroplast. This latter component was similar in reflectance to those of the residues of both thermal and catalytic runs after solvent (THF) extraction. 


\section{EXPERIMENTAL}

Samples

Table 1 lists the samples received from Consol for this study. Approximately one gram of each sample was received. They were found to be of varying particle size and/or of loose or slightly tarry consistency. Eighteen $(\# 1-\$ 18)$ of the twenty gold-tube carbonization samples were supplied to Penn State with extensive analytical information and with a full history of operating conditions. Two of the samples (\#19 and $\# 20$ ) were supplied as blind control samples with no documentation. The first twenty samples were nondistillable residual materials that might contain insoluble organic matter (IOM) and coal-derived mineral matter and/or catalyst. The remaining eight samples (\$21-\#28) designated for reflectance microscopy were the THF insoluble portions of the process stream samples corresponding respectively to samples $\# 7-\# 14$.

Table 2 provides some of the process and analytical information supplied by Consol. Briefly, samples have be'sn provided from three liquefaction facilities (Lummus, Wilsonville and HRI). Twelve of the samples (\#3-\#14) are recycle or interstage (after first reactor) resids from the Close-Coupled Integrated Two-stage Liquefaction (CC-ITSL) Wilsonville process. It should be noted here that recycle samples not only have been processed through the second stage reactor, but have been subjected to down-stream processing steps which may include low pressure flashing, vacuum flashing and deashing before sample collection. All but four of the Wilsonville samples were composites of a number of run periods (exceptions are $\$ 3-\$ 6$ which were from single operating periods). Samples 1 and $\$ 2$ were from the Lummus ITSL process development unit, whereas samples $\$ 15-\$ 18$ were from the HRI ebullated-bed bench unit 227 .

In addition to the process information, analytical data provided by Consol are also listed in Table 2. These include percentages of ash and IOM, ultimate analyses, the proton types identified by ${ }^{H}$-NMR spectroscopy, and the phenolic hydroxyl concentration determined from FTIR. These data are to be correlated with the results of the gold-tube carbonization runs.

Based upon this analytical information Consol has provided an array of samples from a wide variety of subbituminous and bituminous feed coals. Each sample set contains non-distilled coal liquids, one from the typically higher temperature first-stage reactor (interstage) and the other taken following second-stage reaction and down-stream processing (recycle). These sample sets should provide knowledge about the effectiveness of the second-stage reaction and processing in diminishing the occurrence of retrogressive reactions. Most of the two-stage liquefaction processes were run with catalyst materials in both reactors, except Wilsonville run 250 which was run in the thermal/catalytic mode. In comparison to Wilsonville run 257 (catalytic/catalytic mode), this sample set could provide some understanding of the influence of catalyst during the first-stage reaction. The Ohio 6 samples from Wilsonville are also of interest in that one of feed coals 
(Holmes mine, 3 and 4 ) was apparently weathered. During operations at Wilsonville, oil properties and total conversion of this coal were significantly lower than in a previous Ohio \#6 run. When a fresh supply of unweathered coal was obtained from a different mine (Crooksville, \#5 and \#6) conversion and product yield impreved. Finally, the Black Thunder HRI runs provide a comparison between as-received (run $\mathrm{CC}-2$ ) versus thermally dried $(C C-5)$ coal $(25.4 \%$ vs $5 \%$ moisture).

A $250 \mathrm{mg}$ portion of each sample designated for the gold-tube experiments was removed for later inspection under an optical microscope. The remaining sample was crushed with a small mortar and pestle to a very fine particle size (not measured) and homogenized. The THF-insoluble residues were prepared asreceived for optical microscopy.

\section{Gold-Tube Carbonization Procedure}

The procedure followed for gold-tube carbonization has changed in many small ways from the procedure described under "Background". Variations from the original technique resulted because the old equipment used during the 1970 s is no longer available and the new equipment has a different design and control system. The following is an account of the detailed procedure followed during the course of our gold-tube investigations.

\section{Tube Preparation}

Five feet of high-purity gold tubing of $0.5 \mathrm{~cm} 0 . \mathrm{V}$. was ordered from Engelhard Corporation and received in December 1990. For each experiment a $-5.7 \mathrm{~cm}$ section of tubing was cut with a pipe cutter and the ends cleaned of filings. Each section was then pre-conditioned by immersing in a $50 / 50 \mathrm{v} / \mathrm{v}$ solution of $\mathrm{HCl}$ and deionized distilled water and boiled on a hot plate for 1 $h$. This procedure was followed to remove traces of iron that might be present following the manufacture of the tubing. Each section was washed in deionized water for $10 \mathrm{~min}$, dried with acetone and annealed in an open flame to soften the tubing for welding. One end of the tube was arc welded using the device illustrated in Figure 2. A scribe was used to mark each tube with the appropriate sample number and the initial tube weight recorded.

Finely ground samples were introduced into the gold tubing using a funnel that was fashioned from narrower 0.D. (3 mm) gold tubing. The funnel was constructed so that samples could be loaded into the bottom of each reaction tube. Any sample adhering to the inside walls of the reaction tube would interfere with the final welding. Between each loading the funnel was washed in acetone and annealed to prevent contamination of the next sample. Approximately $250 \mathrm{mg}$ of samples was weighed out, transferred to the appropriate reaction tube and the sample weight recorded.

Using the apparatus and procedures illustrated in Figure 2 the reaction 
tube was first evacuated with a vacuum pump for 5 min while being cooled in a liquid nitrogen bath. A stream of nitrogen gas was bled into the tube and the top crimped tightly. Additional liquid nitrogen was added to the cooling bath and the top end welded shut. Gold tube plus sample weights were recorded. To evaluate weld competency each sealed reaction tube was immersed in boiling water for 5 min before being placed in cold water and then reweighed. Samples were rejected as leaking if there was any significant weight gain $(>2 \mathrm{mg})$. About $10 \%$ of the samples were rejected during this evaluation causing both loss of tubing and sample.

\section{Carbonization}

Experiments were designed so that four samples could be reacted during a single carbonization run. As shown in Figure 3, sample capsules were loaded into a crucible, with quartz wool separating the samples and holding them tightly against the interior crucible wall. The crucible was placed in the furnace, the closure nut tightened, and the furnace righted so that the tubes became vertically oriented. Before heating, the system pressure was brought to -3340 psi $(0.23 \mathrm{kbar})$ using argon as the pressure-transmitting medium, the furnace controller set points were selected for the upper and lower windings and the heating progran was initiated. Each experiment required about 15 min for the temperature and pressure to equilibrate at $450^{\circ} \mathrm{C}$ and $5000 \mathrm{psi}(0.345$ kbar), respectively. Samples were allowed to soak at this temperature for $1 \mathrm{~h}$ and then the furnace was shut down. Temperature decreased at $19{ }^{\circ} \mathrm{C} / \mathrm{min}$ (about 20 min to reach $80^{\circ} \mathrm{C}$ ). Once the furnace was below $100^{\circ} \mathrm{C}$, the pressure was slowly let down at about $220 \mathrm{psi} / \mathrm{min}$.

When the furnace reached ambient temperature and pressure the crucible and samples were removed. Each reaction tube was inspected for rupture and weighed. About $5 \%$ of the samples ruptured during pressure let-down; most of the material that leaked from the tubes was gas or liquid condensate. The samples were then placed under refrigeration at $-5{ }^{\circ} \mathrm{C}$ to partially solidify the condensate.

Sample Work-up

Gold-tube samples were removed from refrigeration and immediately reweighed and vented by puncturing the tubes with an X-acto knife. Typically, only gas was released, but occasionally some liquid condensate was also lost with the gass. Consequently, the weight difference between closed and open tubes was recorded as gas + condensate. Following about 10 min of venting the gold tube was cut longitudinally and pried open to expose the solid or tarry carbonization residue. Care was taken not to disturb the sample inside the gold tubing; the tube containing the sample was placed as is into a pre-tared cellulose extraction thimble $(22 \mathrm{~mm} \times 80 \mathrm{~mm})$.

Samples were Soxhlet extracted in $160 \mathrm{ml}$ of pyridine under a flow of 
nitrogen for $48 \mathrm{~h}$. Typically, the extract liquid was clear after $24 \mathrm{~h}$. Following extraction, the thimbles containing the samples were carefully removed and washed about 5 times with absolute methanol to assist in the remova? of pyridine. They were then transferred to a vacuum oven for $48 \mathrm{~h}$ where they were heated for $2 \mathrm{~h}$ at $100{ }^{\circ} \mathrm{C}$ and at $25^{\circ} \mathrm{C}$ for the remaining time. The initial extractions in the winter months were dried to a constant weight to obtain the percentages of pyridine insolubles and solubles. However, as our work extended into the summer a problem developed due to the uptake of moisture by the cellulose extraction thimbles. In the winter months this had not been a problem because of the very low relative humidity. However, in the summer we were forced to allow the vacuum-dried thimbles to equilibrate to their natural moisture content and constant weight. These moisture differences were significant and amounted to tens of milligrams in some cases. The selection of cellulose thimbles had been prompted by our need to obtain the maximum amount of carbonized residue from each gold-tube run for optical microscopy.

Once the final weight had been recorded, the extraction thimbles were cut open and the pyridine insoluble residues recovered. Each solid residue was mixed with a cold-setting epoxy resin in a small sample bottle and then spun in a centrifuge to remove air bubbles and concentrate the residue. After the epoxy had hardened, each sample was molded into a $2.5 \mathrm{~cm}$ diameter cylinder with additional epoxy, allowed to harden and polished using a series of grinding paper and alumina for reflected-light microscopy.

In addition to problems with the extraction thimbles, in some cases we obtained weights of carbonized residues that were less than the total ash plus IOM reported by Consol. To obtain better closure with process stream inerts and to determine if there might have been a sampling problem, all resids designated for gold tube carbonization were Soxhlet extracted using the same procedure described for the carbonization residues. Gold-tube carbonization and extraction results are listed in Table 3.

\section{Petrographic Analysis}

To evaluate the amount and type of mesophase-derived carbon produced during carbonization a special point-count technique had to be employed because of the extremely small quantities of material generated during the gold-tube carbonization. Step distances between fields of view were limited to 300 microns, and identifications were made at three grid points within each field, the distance between the grid points being 100 microns. Even with this increase in grid-point density it was not possible to obtain the 500 identifications necessary to reach a repeatability of $+/-1$ to $2 \%$; the surface areas available for analys is allowed between 39 and 400 counts only. In two cases, where the entire product consisted of only a few particles, it was necessary to visually estimate the composition. Because of their very fine size, residue particles rarely overlapped more than one grid point. This fine particle size and the generally uniform mixing of components are factors 
which would aid the precision of the analyses.

The following components were identified in the point-count analyses of the gold-tube residues:

Low-Reflecting Isotropic This pitch-like material is one type of vitroplast $(5,8,9)$. Because it is believed to have formed by precipitation from the coal-derived liquids rather than by simple melting of coal, it is the variety known as "secondary vitroplast". Its very low reflectance places it clearly in the category of "low-reflectance vitroplast", also known as hydroplast $(5,10)$. Some studies have suggested that this material is asphaltenic in character. Its low reflectance indicates that the reactions involved in its formation are dominated by hydrogenation rather than retrogressive condensation (Plate Ia).

High-Reflecting Isotropic Two classes of material fall into this category. One is coal-derived inertinite, mainly fusinite and semifusinite. The other is process-derived material, produced through the condensation of liquid products. In some instances, the particle size of the coal-derived material is large enough for typical inertinite morphological features to be recognizable. In other instances, an intimate association with mesophase structures suggests that the material was formed during the hydroprocessing. However, in general it is difficult to differentiate between coal- and process- derived material with a high degree of certainty and the classes have been combined into one category in this series of evaluations (Plate Ib).

High-Reflecting Anisotropic "Coke" This is a minor constituent of the residues, having the high-reflectance and anisotropic siructure typical of metallurgical coke. The fact that this material is found exclusively in the products of Wilsonville resids, suggests that it may be fragments of coke contaminant that have found their way into the feed coal during crushing.

High-Reflecting Anisotropic Mesophase Spheres These bodies have formed out of pre-existing liquids by a process of homogeneous nucleation (11). Mesophase formation during hydroliquefaction is believed to occur because of the exposure of liquid products to adverse reaction conditions (temperature excursions, hydrogen depletion or mass transfer problems). It involves the growth and stacking of planar molecules and then, through the conservation of surface energy, the nucleation of spheres. Because of the orientation of molecules within the spheres, a pronounced anisotropy is visible in polarized light with alignment being parallel to an equatorial plane. The gold-tube test is a means of comparing the propensities of different coal liquids or liquid fractions to undergo retrogressive carbonization and form mesophase. In the context of the work reported here, the possibility must be borne in mind that some part of the mesophase may have been generated during the hydroprocessing which produced the feed for the gold-tube testing (Plate Ia and $\mathbf{c )}$.

Because the feed chemistry influences not only the proportion of 
mesophase formed but also the sphere size (4), an attempt was made to assess the sphere diameters. This evaluation was effected by selecting what was qualitatively judged to be smallest, largest and "typical" sized particle during a visual scan across a major part of the pellet surface; the diameter was then measured by means of an eyepiece reticle.

High-Reflecting Anisotropic Mesophase Mosaics When the proportion of mesophase in a residue or carbon reaches the level where the spheres impinge on one another, bulk mesophase is formed through coalescence. The molecular structure of the mass may be capable of undergoing a realignment, the extent of which depends upon the fluidity of the mesophase at that time. In a wellhydrogenated coal liquid or one with a lower functionality, a greater level of molecular mobility is likely to be maintained, allowing the mesophase to remain fluid and relatively large mosaic or domain sizes to form. In this analysis, mosaic sizes were estimated by measuring the maximum size of isochromatic areas as seen in polarized light and with the insertion of a mineral retardation piate as an accessory (Plate Id).

\section{Reflectance Microscopy}

The eight THF-insoluble residues $(\$ 21-28)$ were prepared into polished sections in a manner similar to that described for the gold-tube carbonization residues. Approximately one gram of material was mixed with an excess of epoxy resin in a glass vial and centrifuged within the vial to concentrate the residue. Once hardened, the glass via? was removed, the sample cut in half longitudinally, and re-embedded in a $2.5 \mathrm{~cm}$ diameter mold. These samples were polished using a series of grinding papers and alumina polishing compounds. For comparison, small quantities $(250 \mathrm{mg})$ of the corresponding whole product samples $(\$ 7-14)$ were prepared in the same manner.

Mean random reflectance analyses were performed on three individual components of each residue and whole-product sample, namely high-reflecting vitroplast, partially reacted vitrinite, and low-reflecting vitroplast. These residue components were selected for analys is because they have been identified as materials derived from either reactive coal macerals (mainly vitrinite) or from liquid products formed during the liquefaction process. Their presences in the insoluble residues and their level of reflectance may suggest some inefficiency in process conditions that has allowed them to escape conversion or has been involved in their formation from liquid products.

All reflectance measurements were conducted using a Leitz Orthoplan/MPV2 microscope photometer system at $625 \times$ total magnification. Because of the very small particle size of residue materials, random reflectance measurements (no stage rotation) were performed. Normally, random reflectance measurements are made without a polarizing lens in the optical train however; in this study a polarizer was used and set to $45^{\circ}$. The size of the aperture permitting light to the EMI 9558 photomultiplier was reduced to a diameter of $1.9 \mathrm{\mu m}^{2}$, 
thereby allowing measurements to be made on particles of $5 \mu \mathrm{m}$. In spite of the wide distribution of reflectance values observed for residue materials, the photoelectric system was calibrated to a single standard glass of known reflectance $(1.009 \%)$.

A total of two hundred reflectance measurements was made on each sample. Analys is of the polished surface was conducted using an imaginary gria with a distance of $-0.5 \mathrm{~mm}$ between measurements and between each traverse across the surface. A particle was identified as one of the three residue components of interest, the measuring spot was placed near the center of the particle and a reading recorded. In this way, the accumulation of reflectance readings also provides the relative concentration of these three components in the residue. Replicate analyses were performed on the THF-insoluble residues to evaluate data precision.

To determine the relationship between the concentration of residue components (high- and low- reflecting vitroplast and partially reacted coal) and the other IOM and mineral components found in the residues, several pointcount analyses were performed. Residue materials that were measured for volume percentage concentration were granular submicron materials, inertinite (fusinite and semifusinite), high-reflecting vitroplast, partially reacted coal particles, low-reflecting vitroplast, mineral matter, anisotropic coke and mesophase-derived carbon. These analyses were determined for two of the I1l.\#6 Wilsonville samples (\$22 and \#27). The analysis was performed using a grid of $0.3 \mathrm{~mm}$ between points and 1 ines across the polished surface. The material falling under the crosshair in the microscope eyepiece was identified and counted. Up to 1000 points were counted, depending upon the sample volume. 


\section{RESULTS AND DISCUSSION}

\section{General Residue Microscopy}

Polished surfaces of the THF-insoluble samples (\#21-28) and whole products of the resid materials ( $\# 1-\# 18$ ) were evaluated qualitatively under the optical microscope. From an initial inspection, residue materials were identified for reflectance analysis. Generally, the THF-insoluble residues are composed of particle agglomerates within which larger particles $(-5$ to -30 $\mu \mathrm{m})$ are contained in a matrix of submicron organic and inorganic materials. The matrix forms between 50 to $70 \%$ of the sample volume, but it is the remaining 30 to $50 \%$ which can be used to interpret reaction conditions. Within these large agglomerates, the organic remnants of the coal or processderived materials and mineral matter are not homogeneously distributed. The organic reninants identified in order of relative concentration are recognizable particles of coal inertinite (fusinite and semifusinite), highreflecting vitroplast, partially reacted coal particles, low-reflecting vitroplast and some anisotropic semicoke derived from mesophase. The proportions of these materials as well as the inorganic species are dependent on the feed coal and rank. Inorganic materials found in highest concentrations were coal and process-derived pyrrhotite $\left(\mathrm{Fe}_{1-\mathrm{S}} \mathrm{S}\right)$, coal-derived carbonate (mostly $\mathrm{CaCO}_{3}$ ) and a smaller amount of quartz ( $\mathrm{SiO}_{2}$ ). An assumption is made that a rather large portion of the matrix contains micron-size fragments of aluminosilicate minerals (dominantly remnants of illite and kaolinite).

High-reflecting vitroplast, which is a plastic pitch-like isotropic phase derived from vitrinite or condensation of coal liquids, was commonly found throughout the THF-insoluble residues and in the whole product resid samples that were not de-ashed (see Plate IIa). As discussed above, vitroplast can form as a low reflecting intermediate material which is capable of reacting fully to form liquid products or which can further condense into a material of relatively high reflectance. As seen in Plate IIa, high-reflecting vitroplast was identified as rounded particles or spheres, having no regular internal structure, and of reflectance intermediate between that of the coal vitrinite and fusinite.

As illustrated in Plate IIb, coal particles can survive the rigors of liquefaction and can be identified by their relatively low reflectance and the presence of bedding planes and association with other macerals. Most of these particles have undergone some reaction, where bedding planes may be separated, particle edges are tattered or rounded, and particle reflectance is slightly higher than the mean reflectance of the coal vitrinite. Although, this general class of particle types includes all macerals, reflectance measurements were made only on the vitrinite portion of the particle.

Low-reflecting vitroplast can be described as the isotropic, hydrogenated, plastic coal-derived material formed from vitrinite. In this report low-reflecting vitroplast will be applied to the solvent-soluble 
component of the whole resid samples and to the low-reflecting insoluble component of the THF-insoluble residues. Plate IIC shows that low-reflecting vitroplast serves as the matrix material for coal- and process- derived inerts in a whole-product sample from the 111 . \#6 Wilsonville run 257 . Following extraction with THF only a small amount of the low-reflecting vitroplast can be identified in the residue. As seen in Plate IId, remnants of the lowreflecting vitroplast are rounded particles of slightly higher reflectance than that seen in the whole product sample.

Gold-tube Carbonization

Quality of Carbonization Data

Results from the gold-tube carbonization experiments are given in Table 3 along with the percentages of ash and IOM (THF-insoluble) reported for some of the resids by Consol, as well as the pyridine-insoluble contents (ash + IOM) obtained from Soxhlet extraction (by Penn State) of the whole-product samples. Furthermore, percentage conversion to pyridine insolubles was calculated by the equation given in Table 3 in an attempt to correct the raw data for ash+IOM content. Negative percentage conversion values suggest that there may be a net production of pyridine solubles during carbonization, although it is more likely that there was variation in the ash+lon content (see below). However, before these data can be discussed in relation to liquefaction operating conditions some understanding of data quality is required.

Table 4 lists the schedule of experiments, the weight percentages of products as well as comments pertaining to operation of the furnace that may explain some of the results. Furnace operations required close control during the initial equilibration of temperature and pressure. Equilibration required at least $15 \mathrm{~min}$, but in two of the experiments ( 2 and 3 ) the operation required 21 to 11 min longer. The longer equilibration time may have resulted in a slightly higher production of pyridine-insolubles in experiment number 2 (samples $\# 6, \# 8, \# 10$ and $\# 12$ ). A relatively strong influence of time on production of insolubles was demonstrated in previous work (Figure 1).

The strong effect of temperature on the production of pyridine insolubles also has been demonstrated. During three experiments, when soak temperature $\left(450^{\circ} \mathrm{C}\right)$ was reached, the selected set point for the upper furnace windings controller caused the temperature to overshoot. This occurred during three experiments $(1,3$ and 5$)$; however, only during experiment number 5 was there a severe excursion for a significant amount of time, i.e. $50^{\circ} \mathrm{C}$ for $-9 \mathrm{~min}$. As can be seen (Table 4), this excursion had a profound influence on the production of pyridine insolubles. We believe that the excursions noted in experiments 1 and 3 are not significant. These irregularities in experimental conditions have certainly influenced the overall weight percentage insoluble production, but not the propensity of a given sample to produce them.

As a further assessment of data quality, one sample was chosen at random 
(\$5 - Wilsonville run 256 using Ohio \$6 coal) and was carbonized in three separate experimental periods (Table 4, experiments 1,3 and 7 ). As shown in Table 3, the production of pyridine insolubles was variable, and, in all cases, less than the pyridine insolubility $c ;$ the whole product. Because furnace equilibration was relatively constant among these experiments, we believe that the observed large variation may result mainly from sample inhomogeneity or from our analytical procedure.

Exploring sample inhomogeneity, some evidence that each of the \#5 replicate samples reacted differently was obtained from inspection of the contents of the gold tube after venting the gases. In each case the carbonized material had a different appearance. For test $\# 5$, the material was a sticky (tarry) mass, in test $\$ 5$ a the material was a solid powder and in test $\# 5 b$ the carbonized residue was basically a single solid particle. Therefore, even though the reaction conditions were fairly reproducible and the starting material had been crushed and stirred when the sample was measured out, the resulting carbonized material was much different. Moreover, microscopic observation of the whole product samples showed that ash and IOM was not uniformly distributed in every particle. Thus, the level of crushing that was achieved may not have been adequate to homogenize the sample.

From an evaluation of the analytical procedure, we believe that Soxhlet extraction together with the small sample size offers the most likely opportunity for variation in our results. In each repeat analys is of sample \#5 mesophase-derived carbon was formed, but the amount of pyridine insolubles determined for the whole-product sample was higher than that of any of the carbonization residues. It seems likely that some of the original coal- and process- derived ash+Ion may have been lost during extraction, and that these losses are variable among different tests. Some of the variability may result from the observed difference in the carbonized residue (tarry vs solid), whereas micron-sized insoluble particles may be more easily washed from a tarry sample and lost during solvent return. The tarry carbonization residues were more readily extracted compared with the solid samples. These small grains may be agglomerated in solid particles and therefore more difficult to be lost from the extraction thimble.

The poor repeatability of the gold-tube carbonization experiments for sample $\$ 5$ and the variation in reaction conditions influences the confidence which can be placed upon interpretation based on our quantitative data. However, in spite of the random variability in these data, it is still possible to offer interpretations of the clearly established trends.

\section{Carbonization - Liquefaction Interrelationships}

Table 5 gives the means and standard deviations of the carbonization results (gastcondensate, pyridine insolubles, pyridine solubles and conversion to pyridine insolubles) by process, although it must be noted that because of significantly different processing steps and coals used, direct comparison 
between the results obtained from these plants may not be justified. However, the gas+condensate values for the Lummus and Wilsonville processes were very similar, whereas those of HRI were approximately double. Further, the pyridine insolubles formed during carionization appear to decrease in the order Lummus > Wilsonville > HRI. The higher pyridine insolubles for the Lummus resids and the higher gastcondensate for the HRI resids appear to be related to both coal rank and to process variables. Another general observation can be made when comparing the results of the Wilsonville recycle and interstage samples. The gastcondensate production was statistically similar regardless of the different feed coals being employed (see Table 1), but the production of pyridine insolubles was found to be about twice as high for the interstage samples. Ash+IOM were found to be slightly higher for the interstage samples (Table 3, except for the Wyodak samples \#11 and \#12), but the difference was not large enough to account for the observed difference in pyridine insolubles produced from the interstage and recycle samples. When considering the percentage conversion to pyridine insolubles, the Wilsonville recycle samples showed a small negative value compared with a larger positive conversion of to pyridine insolubles for the interstage samples.

A general evaluation of the data (not corrected for ash+IOM) suggests that two major trends can be identified in the carbonization data; one that was most certainly related to coal rank or condition and the other related to process variables. From Table 3 it can be observed that resids produced from the Wyodak subbituminous coals (those from Lummus $\$ 1$ and $\$ 2$ and from Wilsonville \#11 and \#12) have produced considerably more pyridine insoluhles. Furthermore, pyridine insolubles are high for the Wilsonville runs using a weathered (oxidized) Ohio $\# 6$ coal (\#3 and \#4) as well as for the interstage samples of the 111 . \#6 thermal/catalytic Wilsonville run (\#14). Figure 4 shows a positive relationship between the percentage of pyridine insolubles produced during carbonization and the concentration of phenolic hydroxyl. This observation was made in earlier gold-tube carbonization work with SRC chromatographic fractions $(4,6)$. As the concentration of heteroatoms increased in a suite of fractions, the amount of pyridine insolubles increased. However, in this study, we are observing the same relationship with resids from coals that have a natural high concentration of oxygen

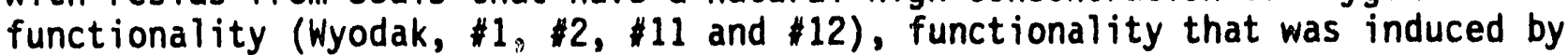
weathering (Ohio \#6 Holmes coal, \#3 and \#4), or functionality resulting from inefficient processing ( $111 . \# 6$ interstage thermal/catalytic run, \#13 and \#14). Note that most of these resids plot in the upper half of Figure 4 (except 13).

Figure 5 attempts to separate coal rank and processing conditions for the suite of Wilsonville resid samples $\$ 5-\$ 12$. This separation uses the raw pyridine insoluble information from Table 3 . These runs were made using different coals and with the plant running in the CC-ITSL catalytic/catalytic mode. Interstage samples were taken after the first, higher temperature reaction vessel, whereas the recycle samples were processed through both the first and second stage reactors as well as additional down-stream processing. Figure 5 shows that the lower rank Wyodak coal produced more pyridine 
irisoluble than the intermediate rank $111 . \$ 6$ and Ohio $\$ 6$ coals. A slight increase in insoluble production was observed with further rank increase, as noted for the Pittsburgh seam runs. As observed above, the interstage sample set showed significantly higher pyridine insoluble values compared with the recycle samples. It appears, therefore, that additional catalytic hydrogenation and down-stream processing of the interstage resids significantly reduces the potential for forming pyridine insolubles.

If the relationship observed for coal rank were applicable to more than one process, one would expect the Black Thunder subbituminous coal from the HRI runs (\#15-\#18) to plot very closely to those of the Wyodak in Figure 5. However, as shown in Table 3, the Black Thunder resids, for the most part, produced very little pyridine insolubles and a great amount of gastcondensate. The reason for this may be process related, in that the chemical properties of the HRI Black Thunder resids are very much different from those of the Wyodak samples. Figure 6 shows that as the total content of paraffinic protons $\left({ }^{1} \mathrm{H}-\right.$ NMR alkyl beta + gamma fractions, Table 2) increases in the resids, the percentage make of gastcondensate increases. All but one of the Black Thunder resids have relatively very high amounts of paraffinic protons, suggesting that either the coal has a greater propensity to form paraffinic compounds and alkylated aromatics, or, and more likely, that the HRI reaction conditions and resid processing system was significantly different than Lummus and Wilsonville for the hydroliquefaction of subbituminous coals.

Figure 7 considers the relationship between percentage conversion to pyridine insolubles and concentration of phenolic $\mathrm{OH}$ in the resids and shows that the HRI Black Thunder samples form a separate relationship compared with the Wilsonville and Lummus samples (except perhaps sample \#2). As found with the raw pyridine insoluble data (Figure 4), in both cases as phenolic $\mathrm{OH}$ concentration increases so does the conversion of pyridine solubles to an insoluble fraction increase. In comparison, for a given level of phenolic $\mathrm{OH}$ the Black Thunder HRI samples appear to produce significantly more pyridine insolubles. The Wyodak Lummus sample ( $\$ 2$ ) may or may not be included with the Black Thunder samples; a large amount of pyridine insolubles were produced during carbonization of this sample owing to a temperature excursion during the experiment (5, Table 4). The Wilsonville and remaining Lummus sample forms a fairly tight relationship which suggests that when the phenolic $\mathrm{OH}$ content of the resids falls below $0.76 \mathrm{meq} / \mathrm{g}$ there may be a net production of pyridine solubles during the gold-tube carbonization.

Another sample set found to be of great interest was the $111 . \# 6$ catalytic/catalytic ( $\$ 7$ and \$8) and thermal/catalytic ( $\$ 13$ and \#14) Wilsonville runs. Formation of pyridine insolubles was much greater for the resid which was only reacted thermally (40.43\% for the interstage sample \#14) and far less ( $1.99 \%$ for the recycle sample $\# 7$ ) was produced from gold-tube carbonization when both stages employed catalyst. The remaining samples (interstage catalytic/catalytic 10 and recycle thermal/catalytic \#13) were intermediate in their production of pyridine insolubles. Furthermore, percentage conversion to pyridine insolubles shows a net production for the 
thermal/catalytic runs, whereas a net loss (negative values, Table 3 ) for the catalytic/catalytic runs. This data set suggests that the greater the degree of catalytic processing the less propensity there is for coking within the reactors.

Petrography of Carbonized Products

The results of petrographic analyses of the gold-tube, pyridine-insoluble residues are given in Table 6 . Two of the carbonization residues were reanalyzed (\#7 and \#14) to determine the mean variation. Analysis of this information revealed that the variation was different for each sample (ranges between $4.4 \%$ and $2.0 \%$, respectively).

Generally, all of the gold-tube carbonization runs produced a mesophase that either resulted in sphere formation or a coalesced mosaic. However, the concentration of mesophase produced and the overall size of the spheres and mosaics were controlled, to some degree, by the presence and concentration of ash $+10 M$ in the original resid samples. If the petrographic categories of high-reflecting isotropic and high-reflecting anisotropic "coke" are combined to represent pre-existing IOM, a reasonable correspondence exists between the petrographic categories and that of the pyridine insolubles (PSU, \%ash+IOM) reported in Table 3 . The sizes of spheres and mosaics were typically smaller when the percentage ash+IOM was large. Obviously, these insoluble materials have interfered with the growth of mesophase.

With regard to plant and process control, the total volume percentage of mesophase (spheres + mosaics) produced from the Wilsonville samples was found to be greatest with the interstage samples except in one case (\#14, $111 . \# 6$, thermal/catalytic). A greater percentage of pyridine insolubles was produced from the interstage sample as well, suggesting that single-stage catalytic hydrogenation has a greater potential to lead to plant coking problems. Because the Wilsonville samples contained a large amount of ash+IOM, sizes of the isochromatic areas were rather small. The average size of spheres was found to be relatively large for two of the $111 . \$ 6$ recycle samples ( $\#$ and \#13), suggesting a greater molecular mobility. Because neither of these samples produced much pyridine-insoluble material during carbonization (Table 3 ), these recycle resids are less likely to form a significant amount of mesophase.

Just as past experience has demonstrated that the $111 . \# 6$ coal has a greater propensity for coke formation during non-catalytic liquefaction (1), processing of the Wyodak subbituminous coal also has lead to reactor deposits containing mesophase (2). However, inspection of the two Wyodak data sets (\#1 - $\$ 2$ and $\$ 11$ - $\$ 12$, Tables 3 and 6 ) showed that, although these runs produced significant pyridine insolubles, only the one Lummus sample (\#2) produced a large quantity of mesophase. The other three Wyodak samples ( $\$ 1, \# 11$ and $\# 12$ ) produced significant amounts of low-reflecting isotropic carbon. The presence of this material may explain the relatively large amount of secondary high- 
reflecting vitroplast observed in the Wyodak THF-insoluble residues (see next section).

As stated above, the Black Thunder (HRI) samples did not produce a large amount of pyridine insolubles. However, nearly all of the carbon produced was found to be mesophase, particularly for the two-stage samples (\#16 and \#18). The largest mesophase spheres and mosaic areas were produced from the twostage runs, whereas smaller spheres and mosaic were formed from the single stage. Previous investigations have shown that SRC from short-contact time runs leads to the production of more pyridine insolubles with mesophase of smaller size compared with SRC from long-contact time runs (4). Also, in comparison, carbonization of the Black Thunder resids produced mesophase of a larger size than those of the Wyodak. One process-related factor that may explain the apparent difference between the Black Thunder runs and the Wyodak, was that the Black Thunder coal was hydrogenated at a much lower first-stage reaction temperature $\left(399^{\circ} \mathrm{C}\right.$ vs $\left.448^{\circ}-437^{\circ} \mathrm{C}\right)$.

A correlation matrix was generated with the petrographic information in Table 6 and the chemical information in Table 2 in an attempt to establish relationships among these data. No significant linear correlations were found betiveen mesophase formation and any of the chemical parameters tested $\left({ }^{2} \mathrm{H}-\mathrm{NMR}\right.$ and phenolic hydroxyl concentrations). Nor were any correlations found between mesophase formation and the percentage conversion to pyridine insolubles.

\section{Reflectance Analys is}

Mean ranjom reflectance results are given in Table 7 for all of the THFinsoluble residues (\$21 - \#28) and their corresponding whole-product samples $(\# 7$ - \#14). In addition, the percentage distribution of readings made on the three residue components (low-reflecting vitroplast, partially reacted vitrinite and high-reflecting vitroplast) are provided. Furthermore, to determine analytical precision (repeatability) four of the THF-insoluble residues were re-analyzed. Results from these duplicate analyses show that vitroplast reflectance could be repeated within an average of $0.008 \%$, whereas partially reacted vitrinite could be repeated within an average of $0.032 \%$. Because hydroplast concentrations were so small statistical assessment was not relevant. Also, the percentage concentration values determined for each component showed that vitroplast volume percentages could be repeated within $1.5 \%$ and partially reacted vitrinite within $1.1 \%$. These levels of repeatability are excellent when the range of reflectance values measured for each component is considered (Table 8 ).

As discussed above, high-reflecting vitroplast reflectance has been shown to be a function of coal rank and process conditions (including reaction temperature and the presence of catalyst). Figure 8 illustrates that for the catalytic/catalytic runs (I11.\#6, Wyodak and Pittsburgh) the interstage process samples generally have lower or the same reflectance compared with the 
more fully processed recycle resids. It further shows that higher processing temperatures tend to generate higher vitroplast reflectance. In the case of the thermal/catalytic I11. \#6 runs, vitroplast from the interstage sample has a much higher reflectance than the recycle sample. With respect to reflectance values from the other resids, vitroplast reflectance was observed to be comparably low for the two sets of $111 . \# 6$ runs (\#21 and \#22 with \#27 and \#28) as are total conversion levels (Table 2). This difference exists even though there was a relatively large difference in first-stage reaction temperatures (421 ${ }^{\circ} \mathrm{C}$ for the catalytic/catalytic and $438{ }^{\circ} \mathrm{C}$ for the thermal/catalytic). This suggests that first-stage reaction temperatures may be kept at lower levels during catalytic hydrogenation than during thermal treatment in order to achieve the same degree of conversion without introducing significant molecular condensation. This conclusion may be supported by the observation that the total aromatic species ( ${ }^{2} H-N M R$ condensed + uncondensed aromatic, Table 2) are greater for the thermal/catalytic runs (26.2\% and $34.5 \%$ ) than for the catalytic/catalytic runs $(19.9 \%$ and $21.8 \%)$.

Reflectance values for partially reacted vitrinite are in all cases higher than the reflectance of untreated coals from the same locality (see Figure 5). Also, with the exception of the Wyodak resids, the reflectance of the recycle samples are higher than those of the interstage samples. This may result from the longer residence time in the system and additional processing. of further interest was the fact that a considerable percentage of the Wyodak resids were composed of partially reacted vitrinite (huminite). It has been observed that subbituminous and lignite coals do not undergo significant thermoplastic deformation and primary vitroplast formation (6) during liquefaction as observed for bituminous coals. However, secondary vitroplast (process-derived) was observed in these Wilsonville process samples. Identification of secondary vitroplast in the gold-tube residues, suggests that perhaps significant retrogressive reactions were occurring during the liquefaction process.

A rather large concentration of partially reacted vitrinite was observed in the I11. \#6 thermal/catalytic samples (\$27 and \#28). This was particularly surprising when comparing operating conditions with those of the catalytic/catalytic $111 . \# 6$ runs ( $\$ 7$ and $\$ 8$ ). The feed rate of the latter was reported to be about double that of the thermal/catalytic runs and the firststage reaction temperature significantly less $\left(421^{\circ} \mathrm{C}\right.$ vs $438^{\circ} \mathrm{C}$, Table 2$)$. The recycle sample ( $\$ 27$ ) appeared to have a relatively high concentration of partially reacted coal based on the reflectance analysis (Table 7 ). To determine whether this was an artifact of the reflectance study, point count analyses were performed on two of the $111 . \$ 6$ samples (\$22 and $\$ 27$, Table 9). Data listed in Table 9 demonstrate that granular residue, high-reflecting vitroplast and mineral matter represents most of each sample and that partially reacted vitrinite is a rather minor component on a whole-residue basis. Nevertheless, the occurrence of partially reacted vitrinite in concentrations greater than a few tenths of a percent is suspicious and suggests that reactor throughput may have been higher than recorded during the thermal/catalytic run (Wilsonville run 250 ). 
Random reflectance values were also collected on the three residue components for the corresponding whole product samples (Table 7). Lowreflecting vitroplast was found in the greatest concentration in these resids $(>53 \%)$. It is further noted that in all cases the residue components were of lower reflectance than the corresponding THF-insoluble materials. One reason for this may be that the low-reflecting vitroplast material reacted with the immersion oil during testing. Not only does its surface change during contact with the immersion oil, but a portion of the low-reflecting vitroplast appears to have been taken up by the oil. Other reasons for lower reflectance values in the whole product include an intimate association of the high-reflecting vitroplast and partially reacted vitrinite with the THF-soluble low-reflecting vitroplast, or that low-reflecting vitroplast may form a thin coating on the surface of the other components thus reducing their reflectance values.

Low-reflecting vitroplast that survived extraction in THF was found in varying concentrations in the THF-insoluble residues. Tattered remnants of low-reflecting vitroplast were found in particularly high concentration in the thermal/catalytic 111 .\#6 samples (\#27 and \#28), although it no longer reacted with the immersion oil. Its presence in the solvent-insoluble fraction points to process inefficiency in the thermal/catalytic mode of operations. If we can assume that THF extraction was complete, the higher concentration of lowreflecting vitroplast suggests an incomplete conversion of asphaltene components of the resid, corresponding to the lower efficiency of thermal hydrogenation. The fact that the $111 . \$ 6$ thermal/catalytic recycle residue has greater amounts of partially reacted vitrinite and low-reflecting vitroplast again suggests that reactor throughput was too high for this particular run.

\section{Blind Samples}

Provided along with the set of eighteen gold-tube samples were two blind samples to be included for carbonization and petrographic analysis. Results for these samples ( $\$ 19$ and $\$ 20$ ) are found in Tables 3 and 6 . As seen in Table 3 , no pyridine insolubles were found in the whole-product samples, the gas+condensate products were similar and at about the same level with those of Wilsonville (Table 5), but the two pyridine insolubles were significantly different. Based on results from the other eighteen samples, we speculate that these are de-ashed Wilsonville samples, \#19 a product of two-stage liquefaction (recycle), whereas $\$ 20$ may be a product of single-stage liquefaction (interstage). The fact that each sample produced a fairly large amount of isotropic carbon (Table 6) suggests that the feed coal may be Wyodak or similar subbituminous coal. Without additional analytical information on these samples further speculation is not possible. 


\section{CONCLUSIONS}

Results of gold-tube carbonization and the production of gas + condensate and pyridine-insoluble have provided a number of interesting correlations with the rank of coals used during liquefaction, process conditions and resid chemistry. Also, the formation of mesophase-derived carbon closely follows the production of pyridine-insoluble materials.

- Twice the amount of gas + condensate was produced following carbonization of the Black Thunder (HRI) resids compared with the other resids provided by Consol which correlated well with a relatively high total paraffinic proton content.

- Coals and the resulting resids having a relatively high oxygen functionality (Wyodak, weathered Ohio\#6 and thermal/catalytic I11.\#6) generally produced more pyridine-insoluble material than other samples.

- Interstage samples from Wilsonville also generated more pyridineinsoluble material compared to the recycle samples, demonstrating the advantage of two-stage catalytic liquefaction for the prevention of plant coking problems.

- Production of pyridine-insoluble material was influenced by coal rank (subbituminous and medium rank hvab giving higher values relative to coals of low rank bituminous coals) and the presence or absence of catalyst in both reactors. However, the coal rank correlation may be confounded by process related factors.

- A substantial portion of the pyridine-insoluble material generated in the gold-tube experiments is anisotropic carbon formed through the development of mesophase. However, the presence of ash and IOM in the resids profoundly effected mesophase development, growth and coalescence.

- As anticipated, a greater amount of mesophase was generated by the interstage samples compared with recycle material.

- Except in one case (sample 12 ), runs using the subbituminous Wyodak coal generally produced a significant amount of isotropic carbon. This may explain the observation of secondary vitroplast in the THF-insoluble residues.

- The size of mesophase spheres and mosaic areas tended to be larger in those resids that produced less pyridine-insolubles and had ?ess IOM. 
Reflectance analyses were performed on vitrini and process-derived materials (high-reflecting vitroplast, partially reacted vitrinite and lowreflecting vitroplast) of THF-insoluble residues from the Wilsonville process. Also determined were the relative concentrations of the different residue components. Our results show that:

- Perhaps owing to a longer particle residence time, high-reflecting vitroplast and partially reacted vitrinite reflectance values are generally lower for the interstage samples compared with the recycle catalytic/catalytic runs.

- Generally, processing temperature appears to have a dominant influence on vitroplast reflectance.

- Vitroplast reflectance as well as total conversion are relatively lower for the two sets of 111 . \#6 runs (catalytic/catalytic and thermal/catalytic), even though there was a fairly large difference in first-stage reaction temperature $\left(421^{\circ} \mathrm{C}\right.$ vs $438^{\circ} \mathrm{C}$, respectively). This suggests that first-stage reaction temperature may be kept lower to achieve similar levels of conversion during catalytic hydrogenation to reduce molecular condensation.

- Low-reflecting vitroplast was found in the thermal/catalytic $111 . \# 6$ recycle sample suggesting that asphaltene conversion may have been incomplete during this run. This fact combined with the observation of partially reacted vitrinite in the sample suggests that residence time in the reactor may have been lower than reported for this run.

- A substaritial amount of partially reacted vitrinite was identified in the Wyodak residues. However, the presence of high-reflecting vitroplast in relatively high concentrations suggests that it may be process derived. 


\section{RECOMMENDATIONS}

As a consequence of this investigation a number of recommendations can be made regarding the gold-tube samples and analytical procedures. It is clear from this work that the presence of ash and IOM in the resids interferes with the development of mesophase during carbonization and our ability to obtain a representative subsample. Removal of ash and IOM should permit greatly improved repeatability for the gold-tube technique.

Furnace control was identified as another problem during the current investigation. One concern in any future study should be to develop the first-order kinetics of the new system to establish standard conditions for that system. Then, if there are differences in heating time or temperature excursions, a better interpretation of the resulting data can be made.

In planning the solvent extraction of the gold-tube carbonization residues our foremost concern was the recovery of the insoluble residue. Thus, cellulose extraction thimbles were used. With such a small initial sample size $(250 \mathrm{mg})$, variations in the moisture content of the thimbles was believed to have contributed to the variability of our results. In future work, alundum extraction thimbles of fine porosity should be used for pyridine extraction and recovery of the insoluble residue should be of secondary importance. The possibility of using larger initial sample sizes should also be considered.

One area of this investigation which needs to be addressed further, is the determination of the relative concentration of mesophase in the IOM of the individual resids. Preliminary petrographic analyses of the THF-insoluble residues showed that mesophase may be present as a process-derived material in some of the samples. To provide a better understanding of the interrelationships between the concentrations of ash+IOM in the resids and the nature of the pyridine insolubles produced during gold-tube carbonization, petrographic analyses of the whole resids should be conducted. These data also may provide information regarding sampling inhomogeneity among the resid samples.

In attempting to determine the precision of the gold-tube carbonization results, it was concluded that poor subsampling of the resid (sample \#5) may have contributed to a rather large variation among replicate tests, even though each sample was finely crushed by hand and homogenized. Inspection of the whole resids under an optical microscope showed that most of the ash and IOM material was of very fine particle size $(<5 \mu \mathrm{m})$ and was not uniformly dispersed throughout particle agglomerates. These observations suggest that a study should be undertaken specifically to improve subsampling. Unfortunately mechanical crushing at room temperatures may not be satisfactory, as many of the resids are tacky solids or would melt due to the heat generated during processing. Liquefying each resid (by heating or by addition of solvent) under an inert atmosphere and stirring may be a more effective means of homogenizing these samples, but the influence of this processing on sample 
quality and the extra time required may not be cost effective. Clearly, this is an area requiring additional research.

Finaliy, the relationship observed between the amount of pyridineinsolubles produced during carbonization and the phenolic hydroxyl concentration of high functionality coals should be investigated further. 


\section{REFERENCES}

1. "Characterization of Mineral Matter in Coals and Coal Liquefaction Residues", EPRI AF 417, RP366-1, Prepared by P.L. Walker, Jr, et al. Penn State University, Report June 1977.

2. Wakeley, L.D., et al., 1979, The Nature of Solids Accumulated During Solvent Refining of Coal, Fuel, Vol. 58, pp 379-385.

3. "Characterization of Mineral Matter in Coals and Coal Liquefaction Residues", EPRI AF 417, RP366-1, Prepared by P.L. Walker, Jr., et al., Penn State University, Report December 1978.

4. Davis, A. et al., 1983, The Microscopy of Mesophase Formation and of Anisotropic Cokes Produced From Solvent Refined Coals, Jour. of Microscopy, vol. 132, pp 315-331.

5. Davis A. et al., 1991, Optical Properties of Coals and Liquefaction Residues as Indicators of Reactivity, Fuel, vol 70, pp 352-360.

6. Whitehurst, D. et al., 1980, "Coal Liquefaction", Academic Press, New York, 378pp.

7. "Enhanced Coal Liquefaction by Low-severity Catalytic Reactions", Davis, A. et al., Final Report to US Department of Energy, Penn State University, DOE-PC-90910-F1, 1989, 175 pp.

8. Mitchell, G.D., Davis, A. and Spackman, W., 1977, A Petrographir Classification of Solid Residues Derived From the Hydrogenation of Bituminous Coals, In: (Ed. R.T. Ellington), Academic Press, New York, pp 255-270.

9. International Committee for Coal Petrology, in press, Internatiorial Handbook of Coal Petrology, 2nd edition, 3rd suppl.

10. Shibaoka, M. and Russe 11, N.J., 1981, A Vitrinite Hydrogenation Model Based on the Microscopic Examination of Batch Autoclave Residues, In: Proc. of the International Conference of Coal Science, Dusseldorf, IEA, pp 453-458.

11. Marsh, H. and Cornford, C., 1976, Mesophase: The Precursor to Graphitizable Carbon, In: "Petroleum Derived Carbons" (Eds M.L. Deviney and T.M. O'Grady), Am. Chem. Soc., Kashington, pp 266-281. 
Table 1

List of Consol Samples

\begin{tabular}{|c|c|c|c|}
\hline Ref. No. & Coal Feed & Source/Conditions & Comments \\
\hline \multicolumn{4}{|c|}{ Gold Tube Carbonization Tests } \\
\hline 1 & Wyodak & Lummus; 3LCF 10; 0111F & Feed to LCF; Resid \\
\hline 2 & Wyodak & Lummus; 3 LCF $10 ; P 0128 \mathrm{~F}$ & Feed to LCF; Resid \\
\hline 3 & Ohio 6 (H) & $W ; 256 \mathrm{~B} ; \mathrm{C} / \mathrm{C}$ & Recycle Stream; Resid \\
\hline 4 & Ohio $6(H)$ & $W ; 256 \mathrm{~B} ; \mathrm{C} / \mathrm{C}$ & Interstage Stream; Resid \\
\hline 5 & Ohio 6 (C) & $W ; 256 E ; C / C$ & Recycle Stream; Resid \\
\hline 6 & Ohio 6 (C) & $W ; 256 \mathrm{E} ; \mathrm{C} / \mathrm{C}$ & Interstage Stream; Resid \\
\hline 7 & Illinois No. 6 & $W ; 257 ; C / C$ & Recycle Stream; Resid \\
\hline 8 & Illinois No. 6 & $W ; 257 ; C / C$ & Interstage Stream; Resid \\
\hline 9 & Pittsburgh & $W ; 259 ; C / C$ & Recycle Stream; Resid \\
\hline 10 & Pittsburgh & $W ; 259 ; C / C$ & Interstage Stream; Resid \\
\hline 11 & Wyodak & $W ; 251-111 ; C / C$ & Recycle Stream; Resid \\
\hline 12 & Wyodak & $W ; 251-111 ; C / C$ & Interstage Stream; Resid \\
\hline 13 & Illinois No. 6 & $W ; 250 ; T / C$ & Recycle Stream; Resid \\
\hline 14 & Illinois No. 6 & $W ; 250 ; T / C$ & Interstage Stream; Resid \\
\hline 15 & Black Thunder & HRI; CC-2 (227-57) & First Stage; FL \\
\hline 16 & Black Thunder & HRI; CC-2 (227-57) & PFL \\
\hline 17 & Black Thunder & HRI; CC-5 (227-62) & First Stage; FL \\
\hline 18 & Black Thunder & HRI; CC-5 (227-62) & PFL \\
\hline 19 & Blind Sample & & \\
\hline 20 & Blind Sample & & \\
\hline \multicolumn{4}{|c|}{ Residue Petrography } \\
\hline 21 & Illinois Wo. 6 & $W ; 257 ; C / C$ & Recycle Stream; IOM \\
\hline 22 & Illinois No. 6 & $W ; 257 ; C / C$ & Interstage Stream; IOM \\
\hline 23 & Pittsburgh & $W ; 259 ; C / C$ & Recycle Stream; IOM \\
\hline 24 & Pittsburgh & $W ; 259 ; C / C$ & Interstage Stream; IOM \\
\hline 25 & Wyodak & $W ; 251-111 ; C / C$ & Recycle Stream; IOM \\
\hline 26 & Wyodak & $W ; 251-111 ; C / C$ & Interstage Stream; IOM \\
\hline 27 & Illinois No. 6 & $W ; 250 ; T / C$ & Recycle Stream; IOM \\
\hline 28 & Illinois No. 6 & $W ; 250 ; T / C$ & Interstage Stream; IOM \\
\hline
\end{tabular}

Note: $T / C=$ thermal/catalytic; $C / C=$ catalytic/catalytic; $P F L=$ pressure filter liquid; $P=$ period; $W=W i l$ sonville; $I O M=$ Insoluble Organic Material (may contain ash); $(H)=$ Holmes Mine; $(C)=$ Crooksville Mine; $L C F=L C-F i n i n g$ Pilot Plant; $F L=$ Filter Liquid 


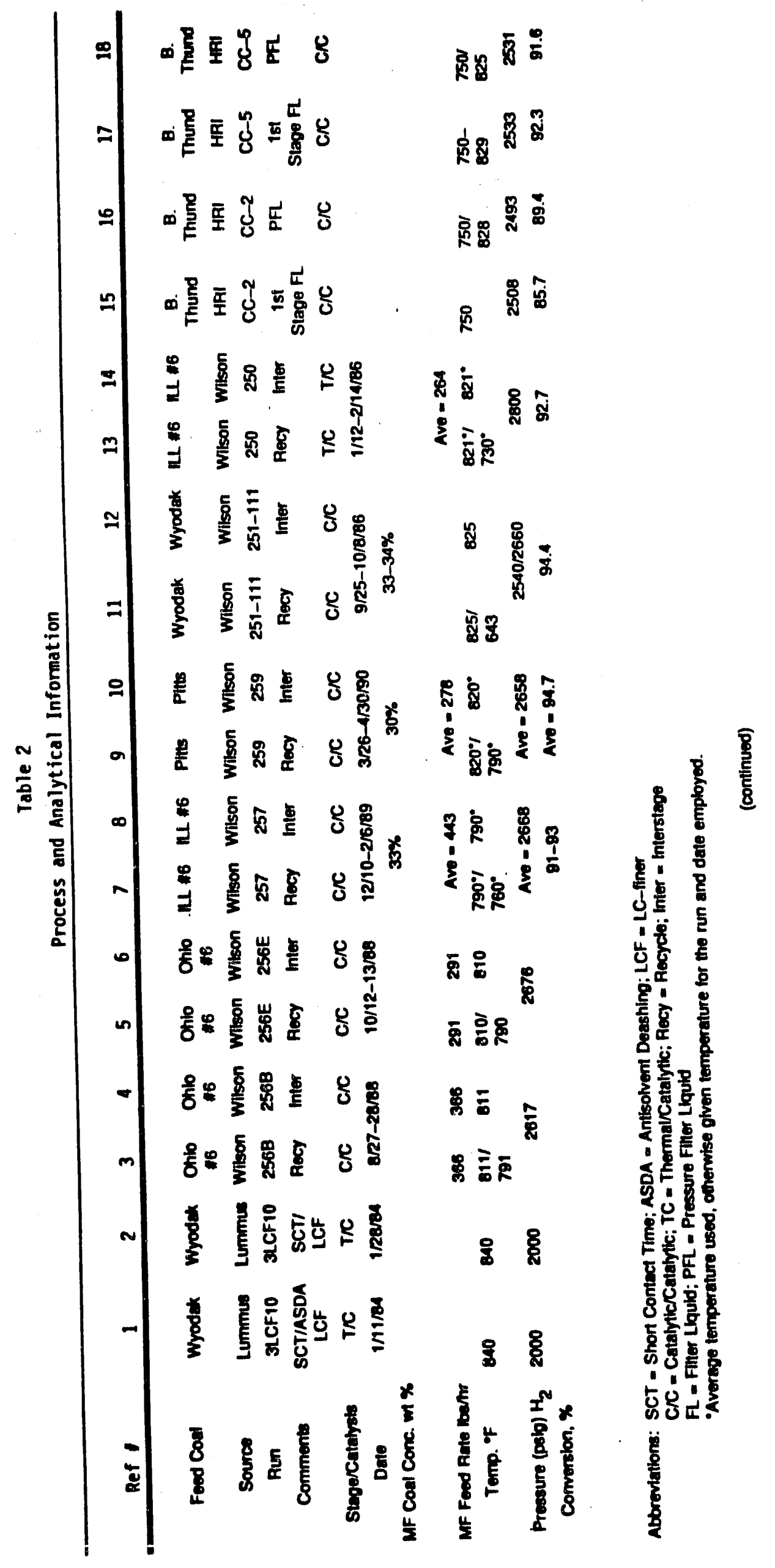




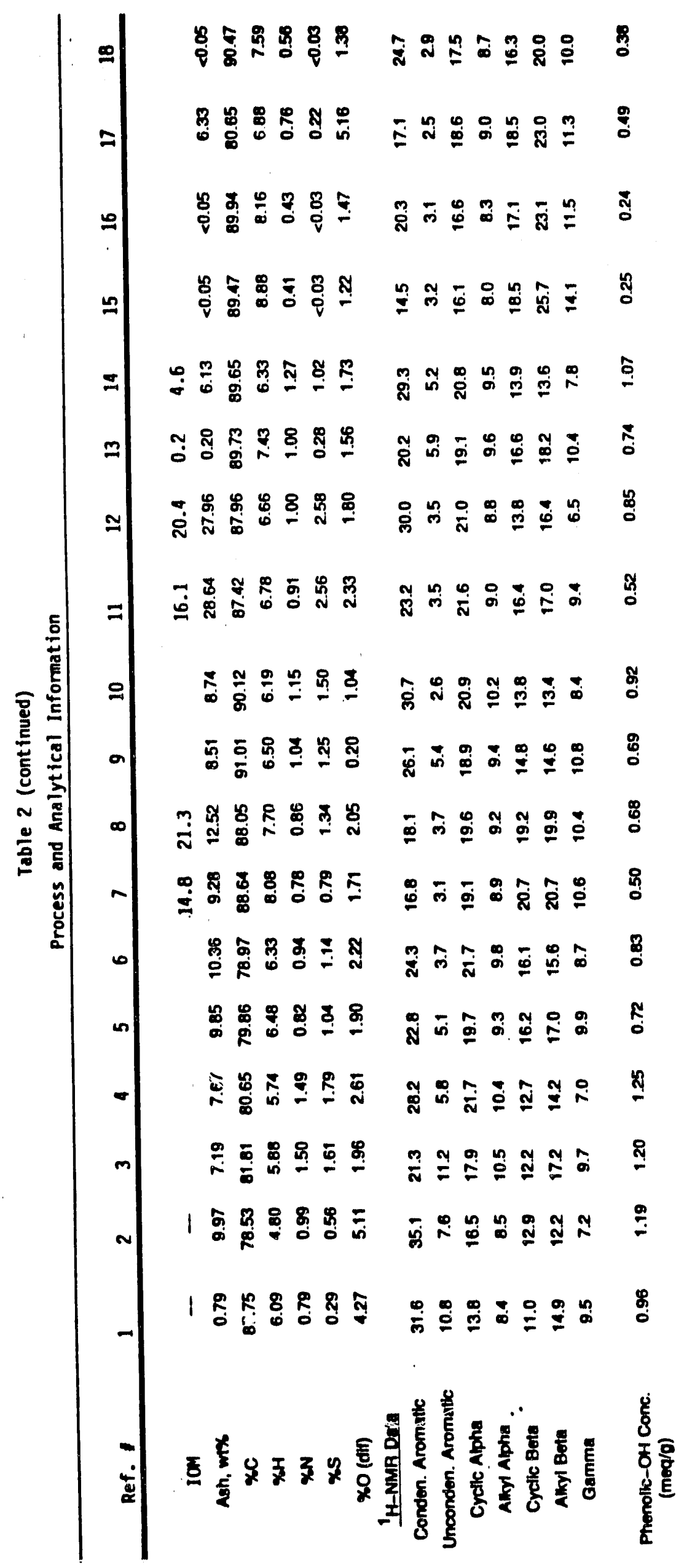




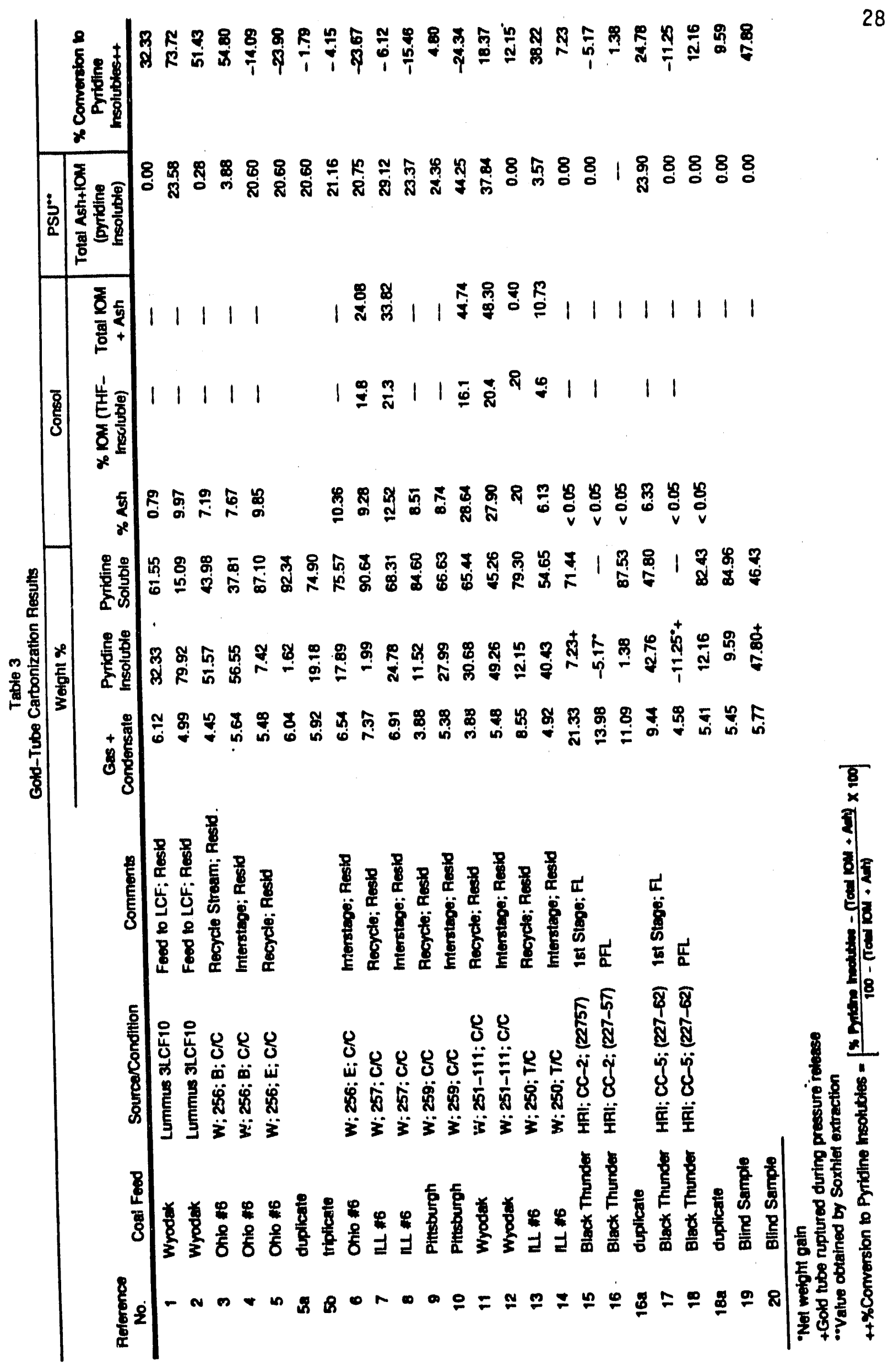




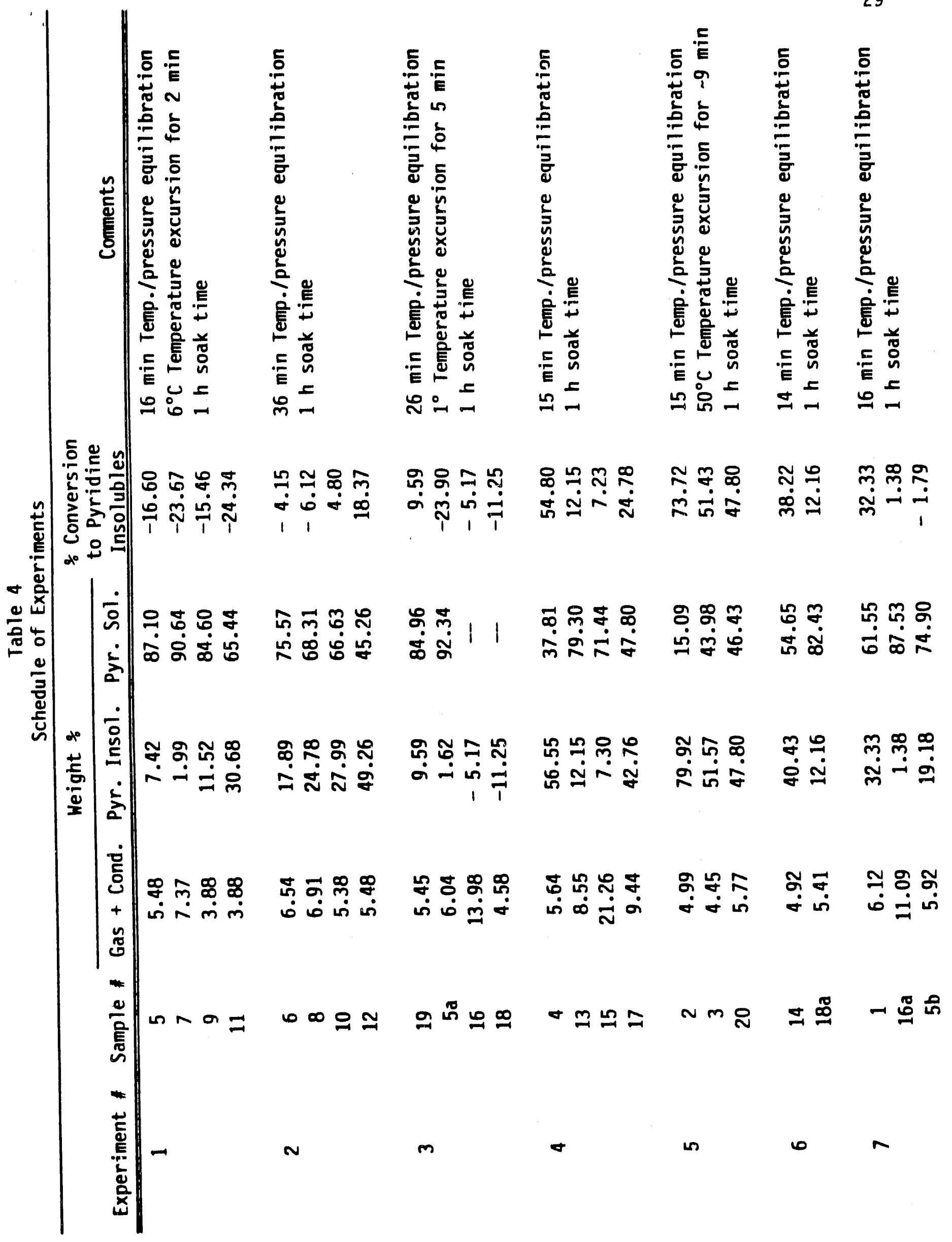




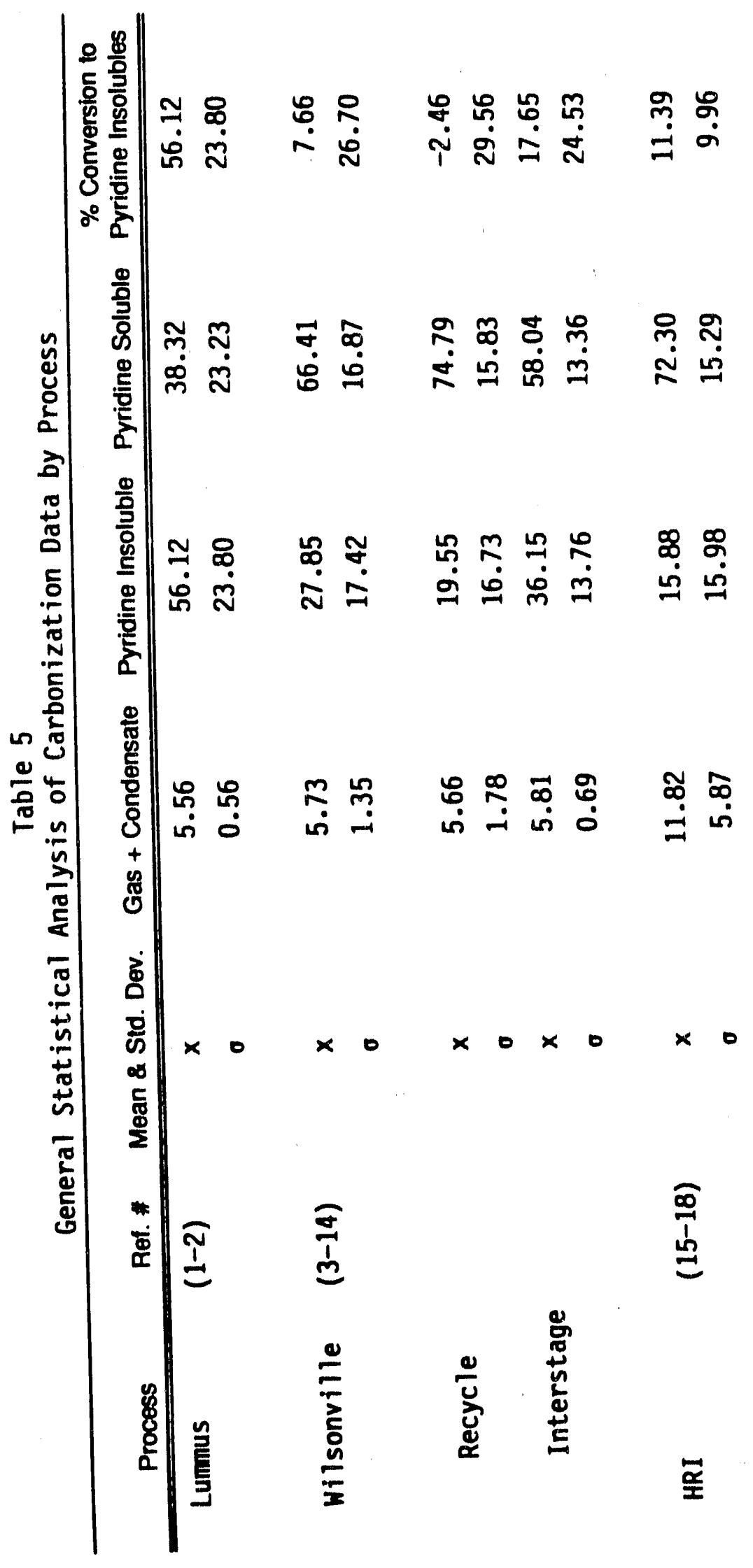




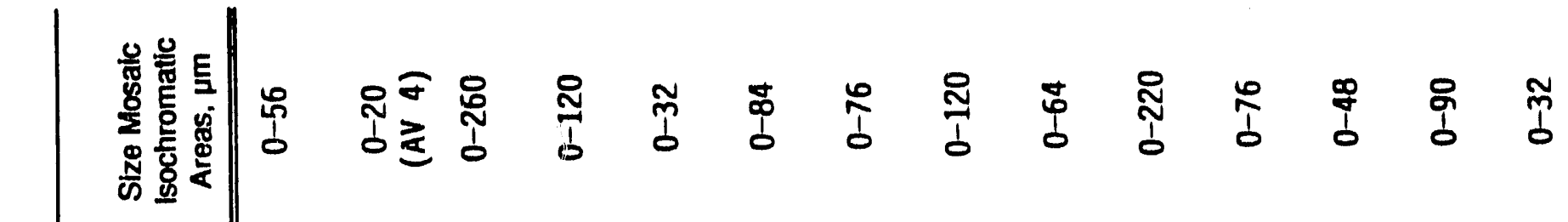

$$
\begin{aligned}
& \frac{\breve{s}}{\bar{g}}
\end{aligned}
$$

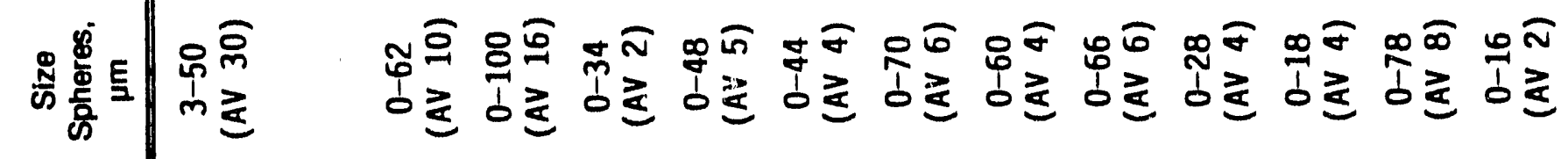

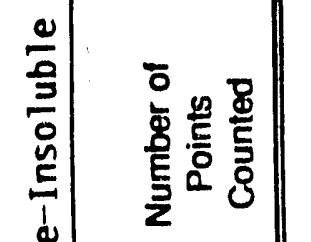

$$
\begin{aligned}
& \text { 임 \& }
\end{aligned}
$$

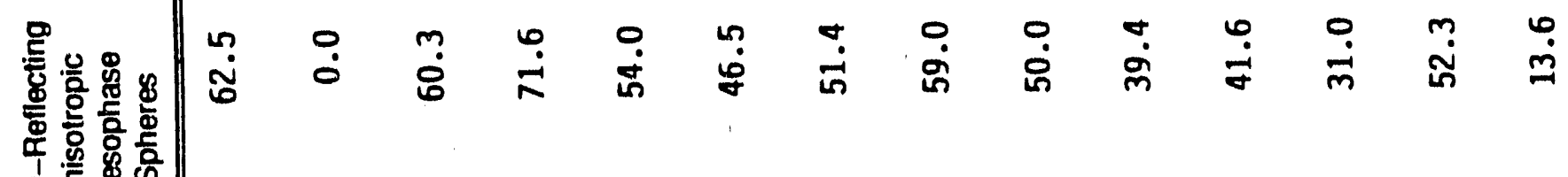

$$
\begin{aligned}
& \text { 总 } \\
& \text { 寅这新 }
\end{aligned}
$$

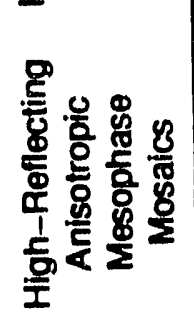

$$
\begin{aligned}
& \text { 응 } \\
& \text { }
\end{aligned}
$$

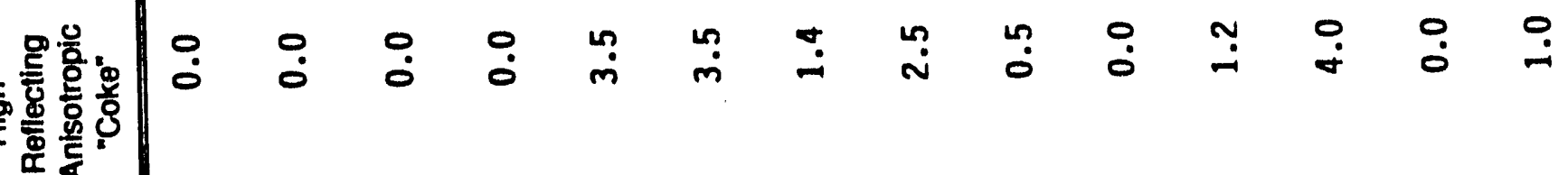

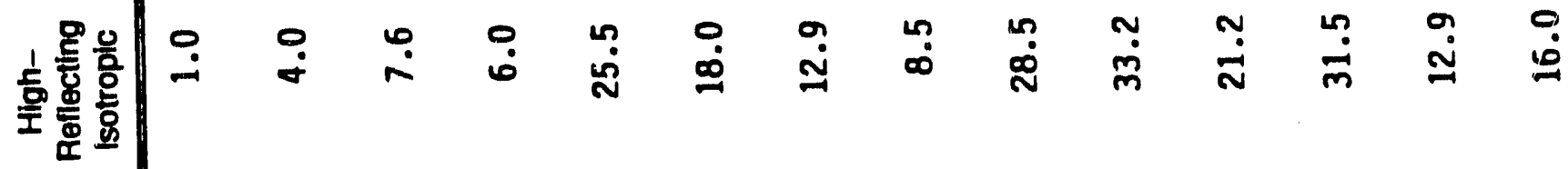

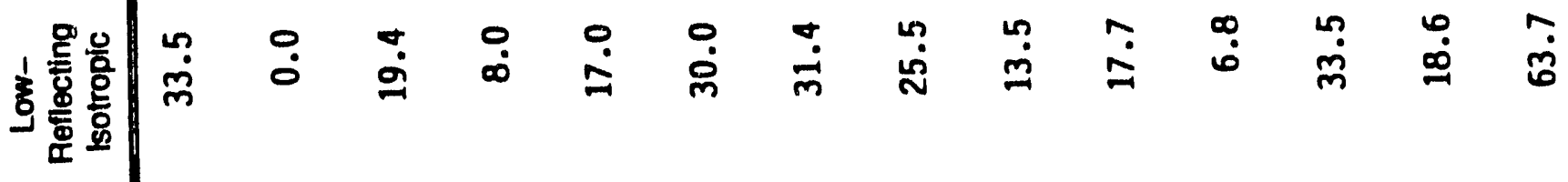

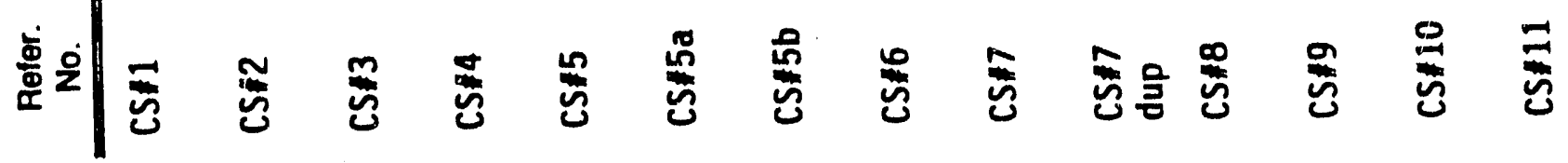




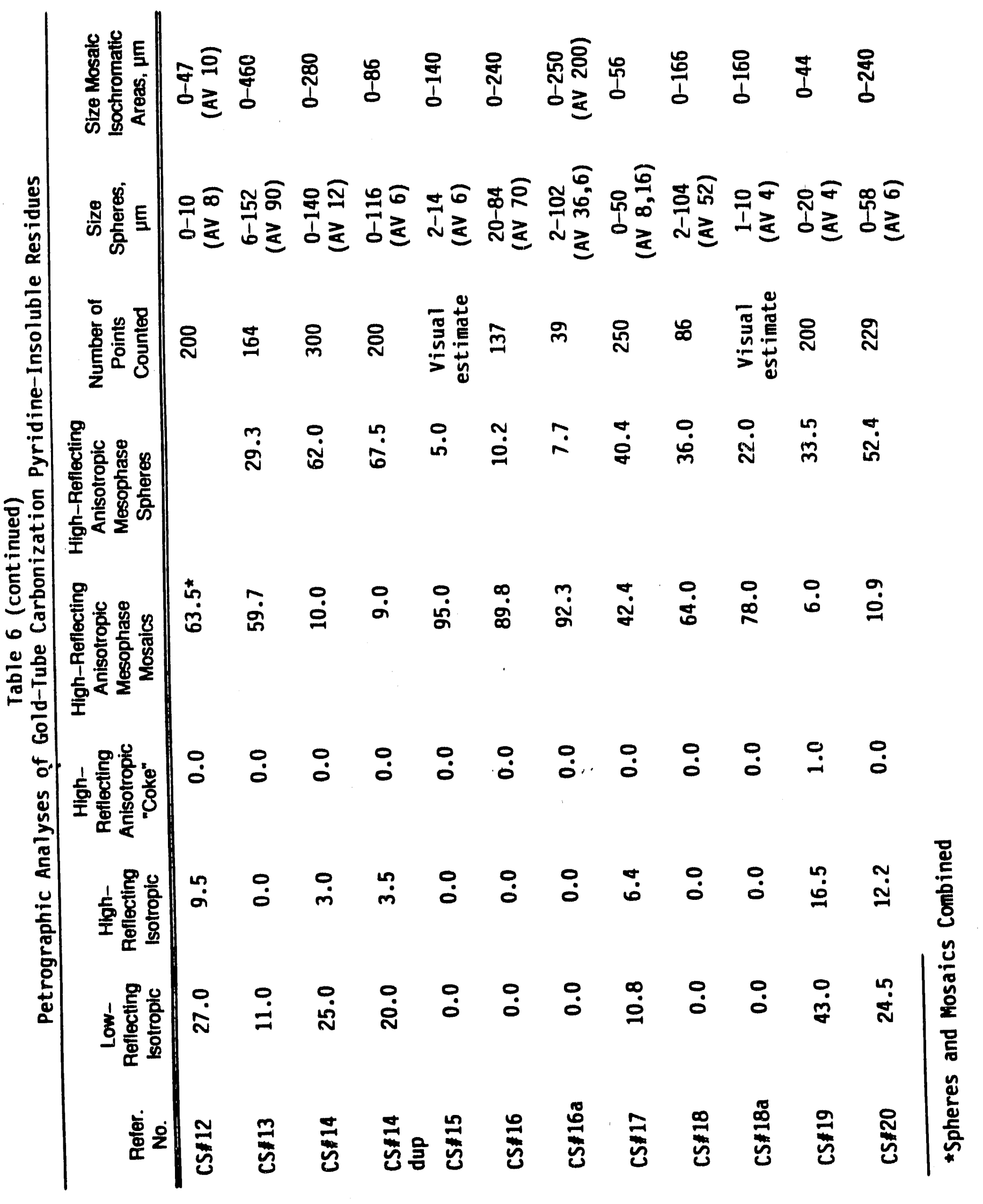




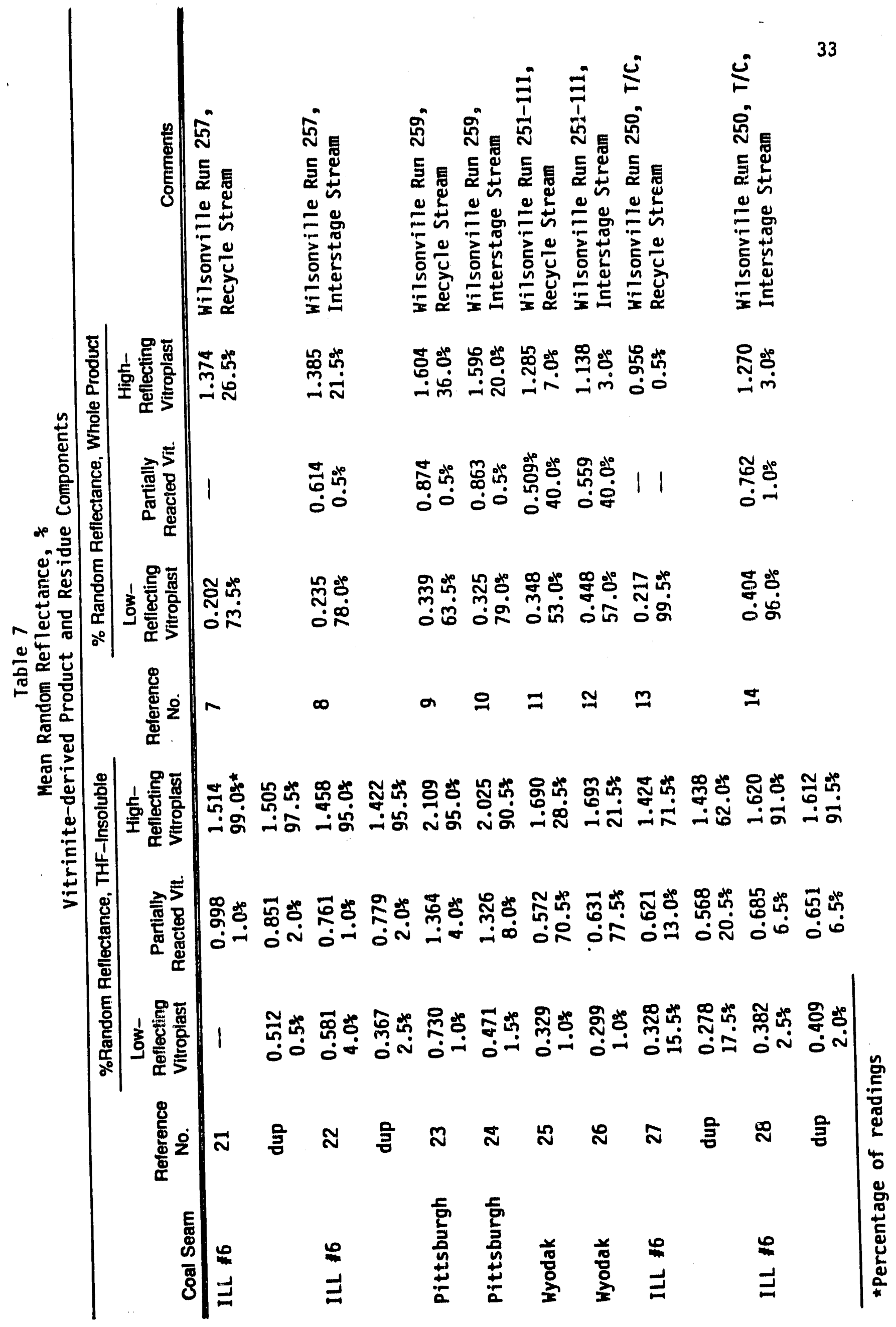




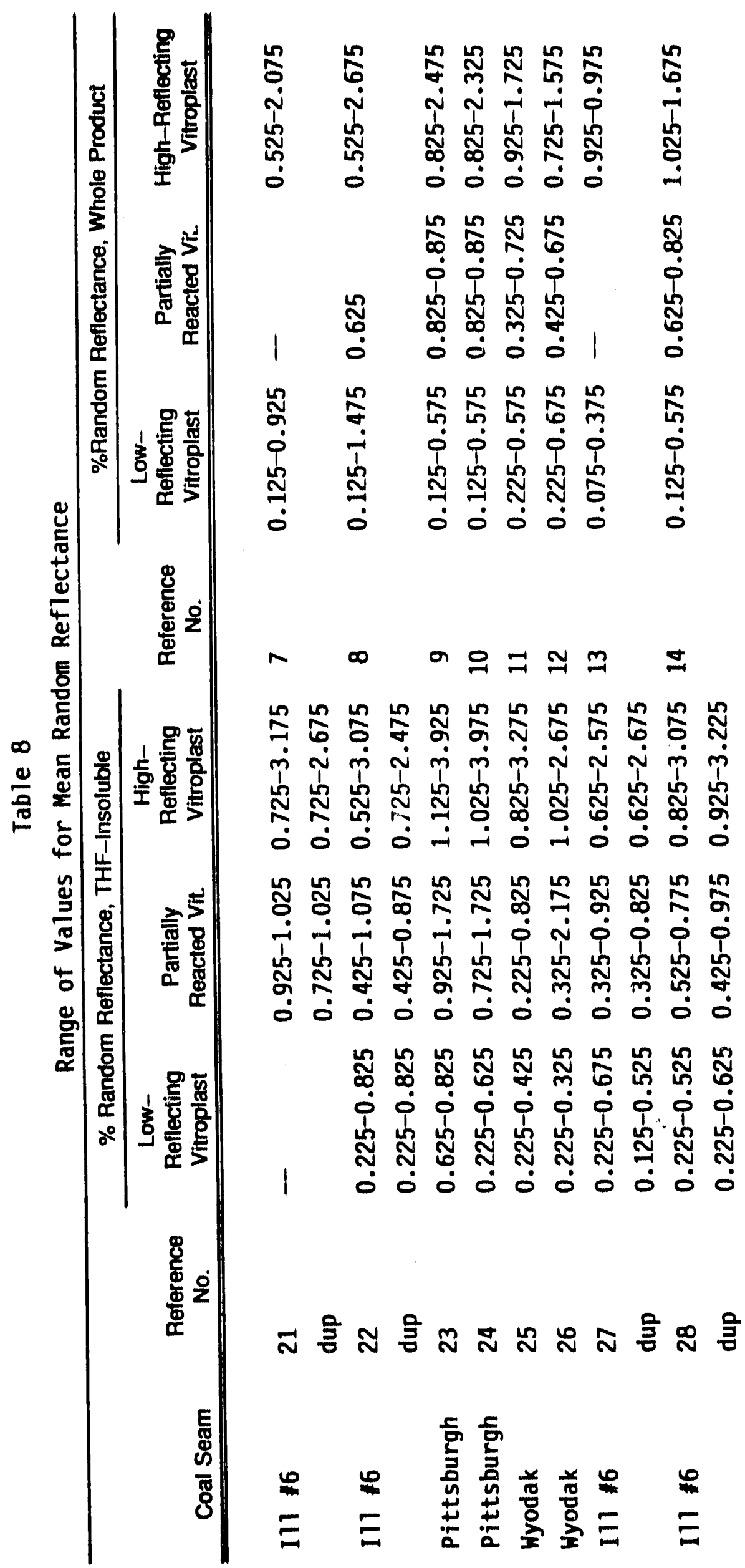




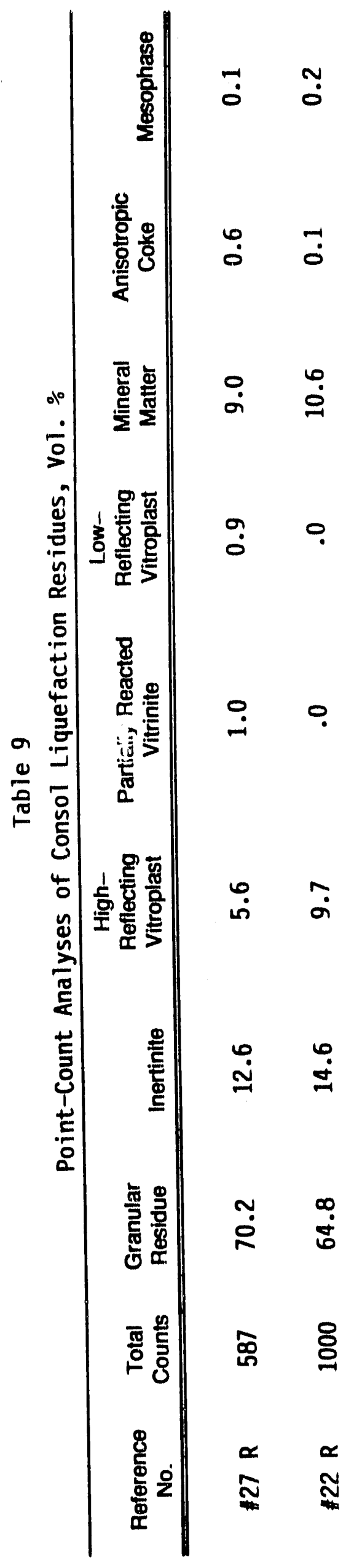




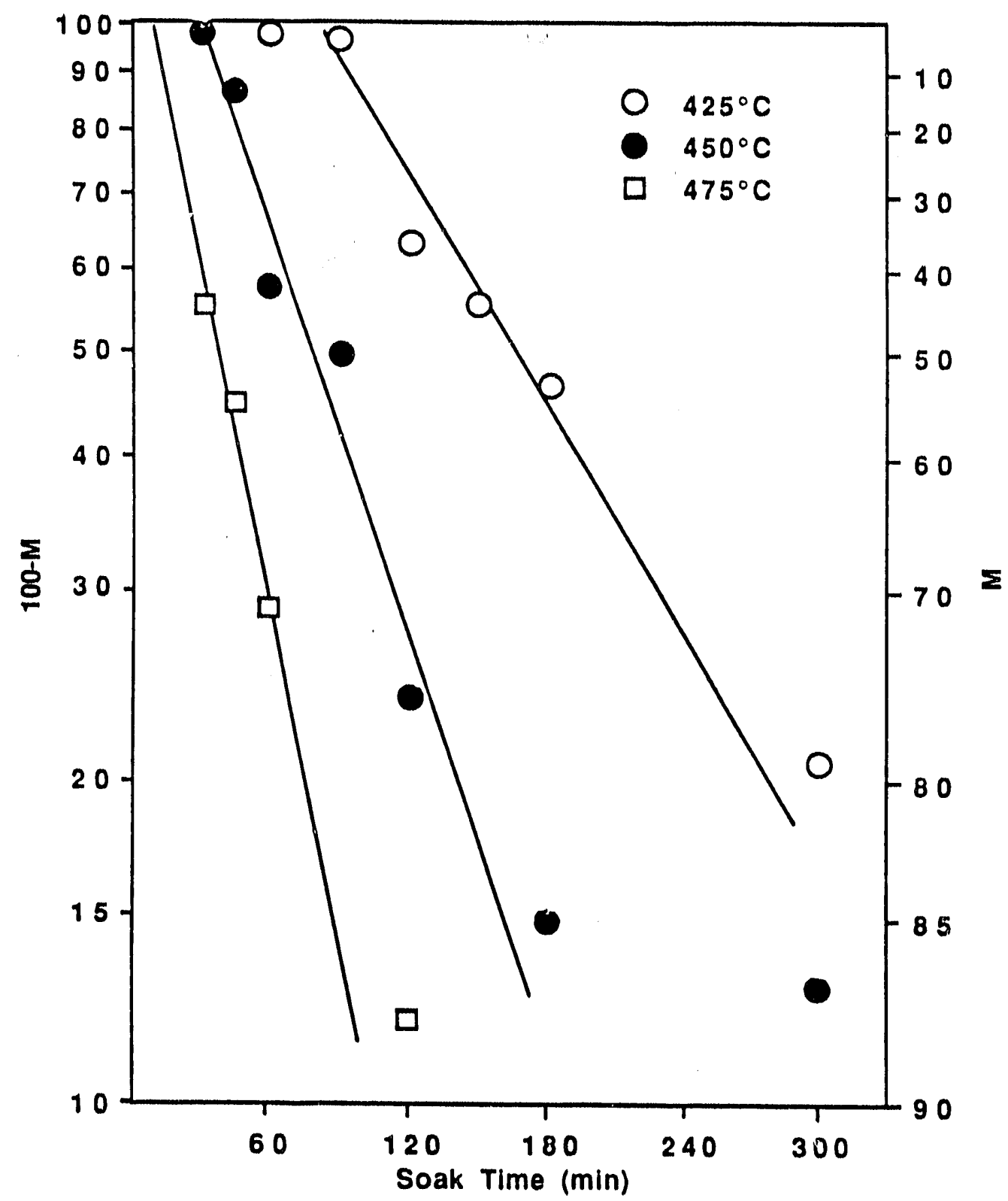

Figure 1. Dependence of the Formation of Pyridine Insolubles (M) from Illinois No. 6 (Monterey) SC-SRC $\left(\mathrm{N}_{2}, 5000 \mathrm{psi}\right)$ on Temperature and Soak-Time (Ref. 3) 


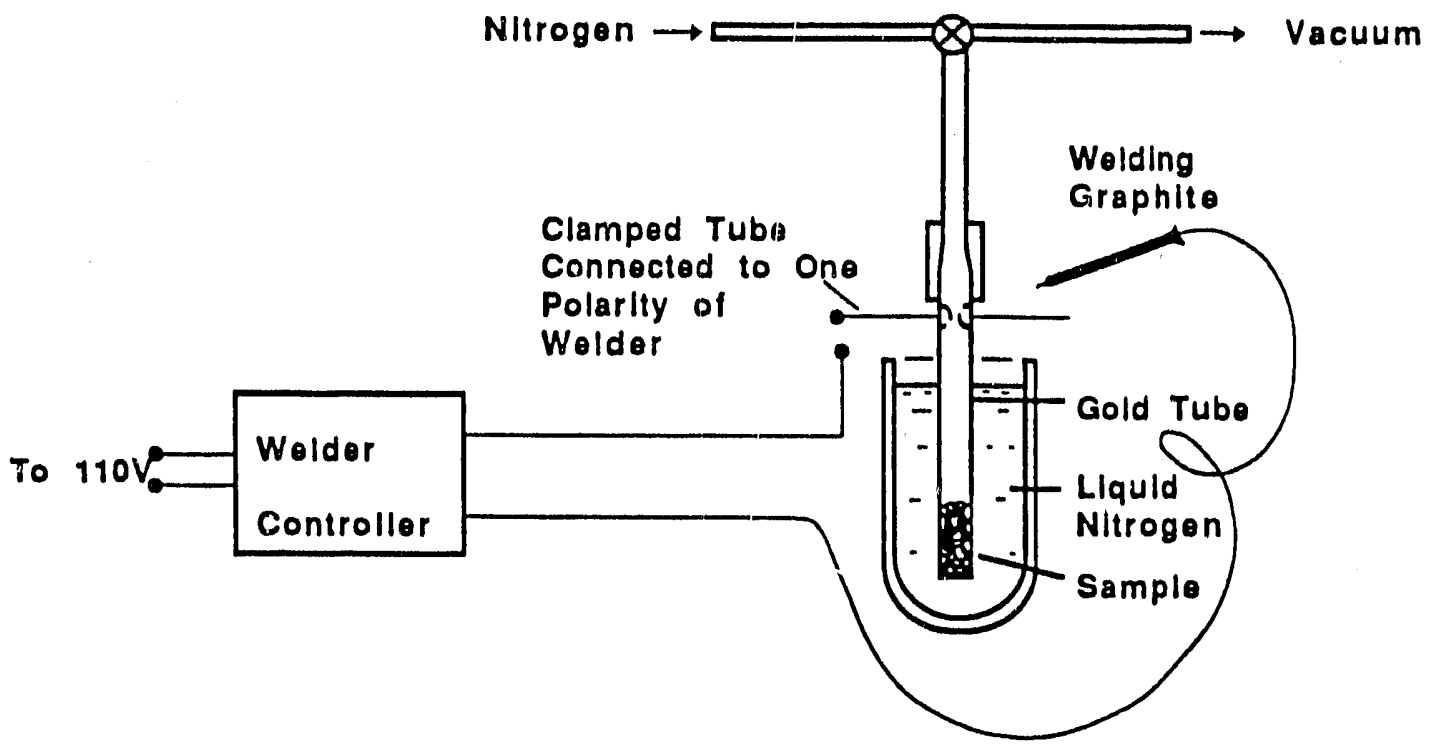

Figure 2. Tube Welding Apparatus (from Ref. 3) 


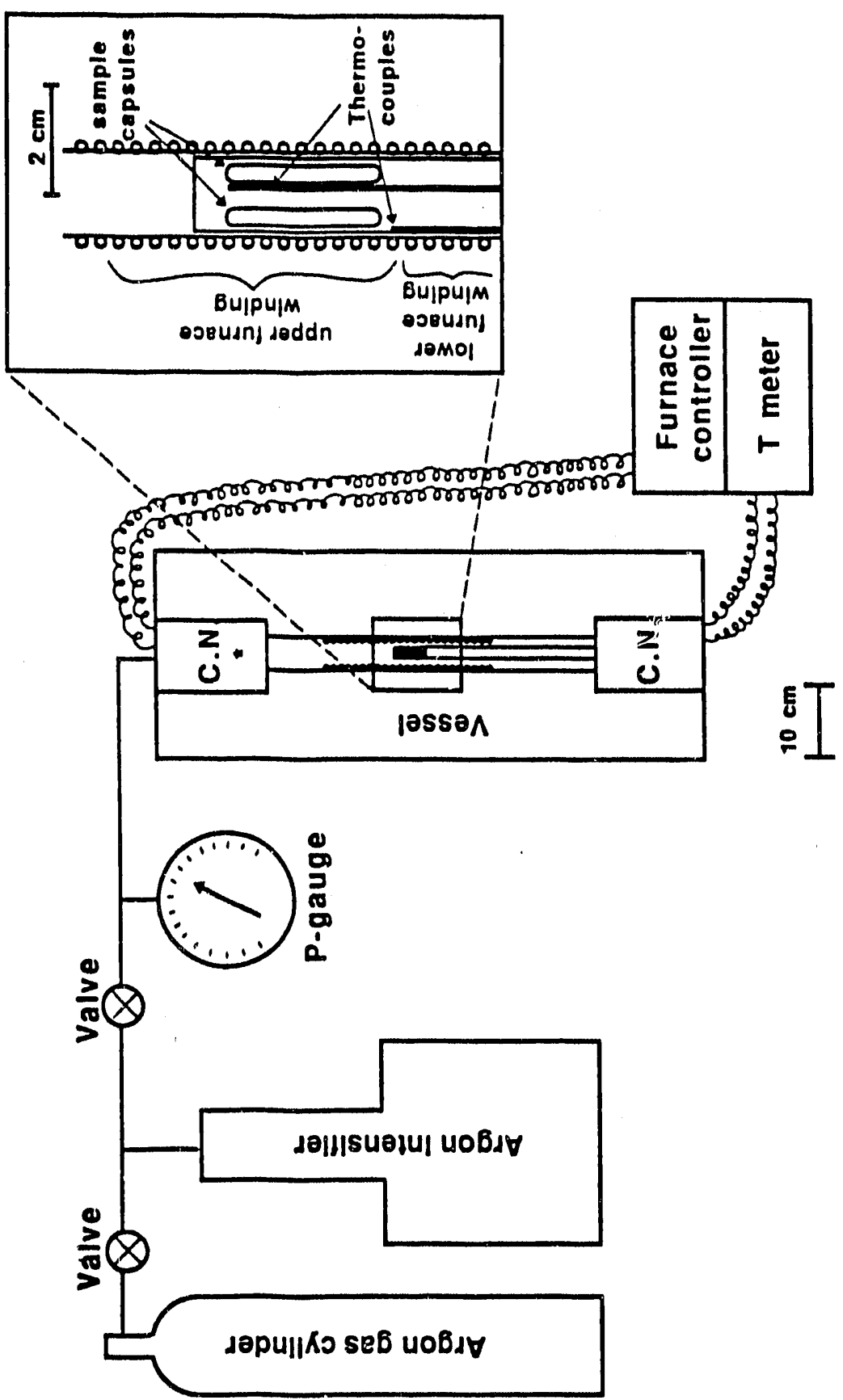

5
5
$\frac{5}{5}$
$\frac{0}{0}$

5

(1)

3 응

$\frac{5}{0}$

II

$z$ क

$\omega$

क

논

5

ญ

도ํ

통

5

$\frac{1}{2}$

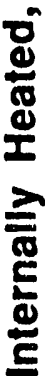

m

ํㅗㄴ 


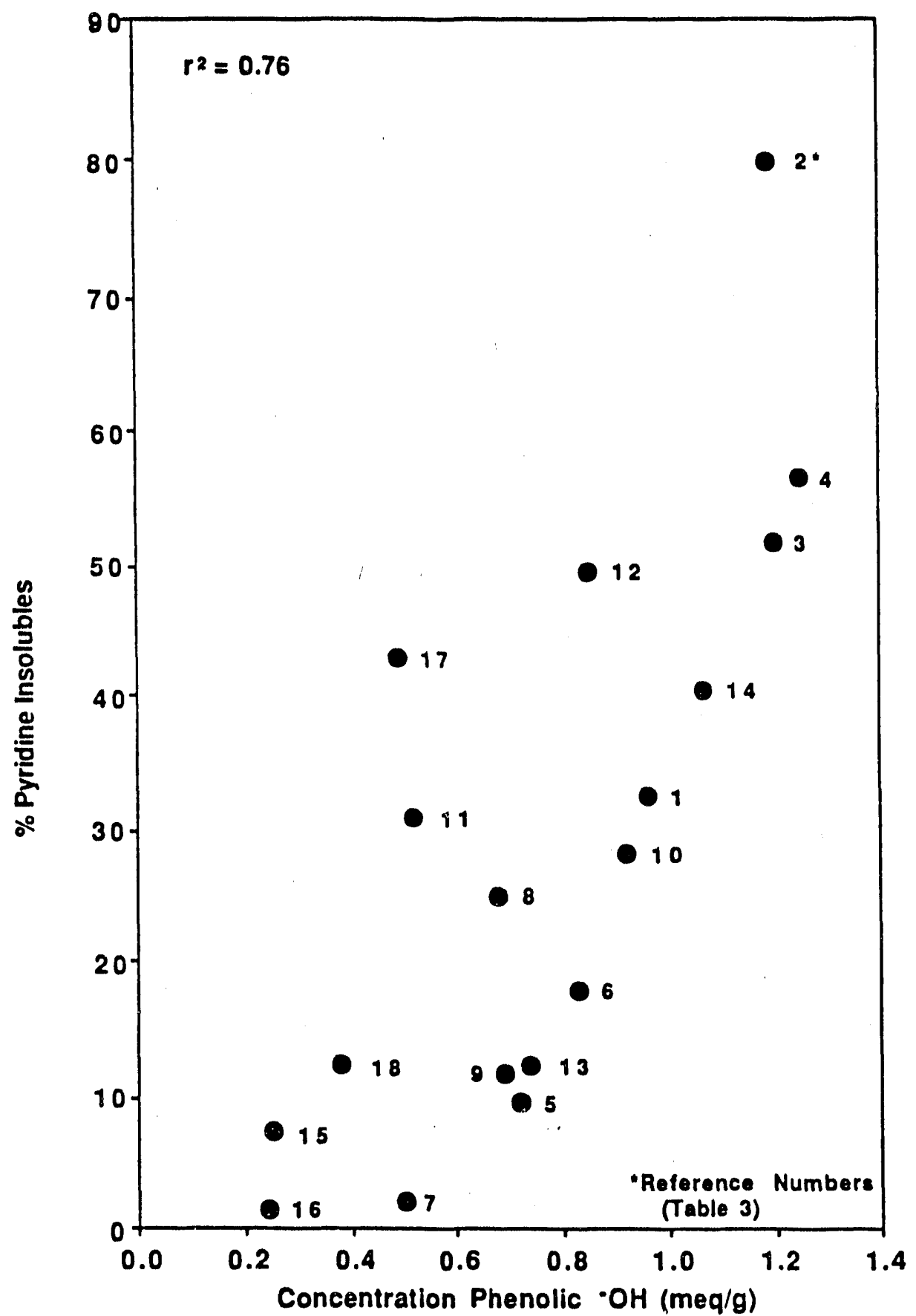

Figure 4. Relationship between Pyridine Insoluble Production during Gold-Tube Carbonization and Concentration of Phenolic OH in Resids 


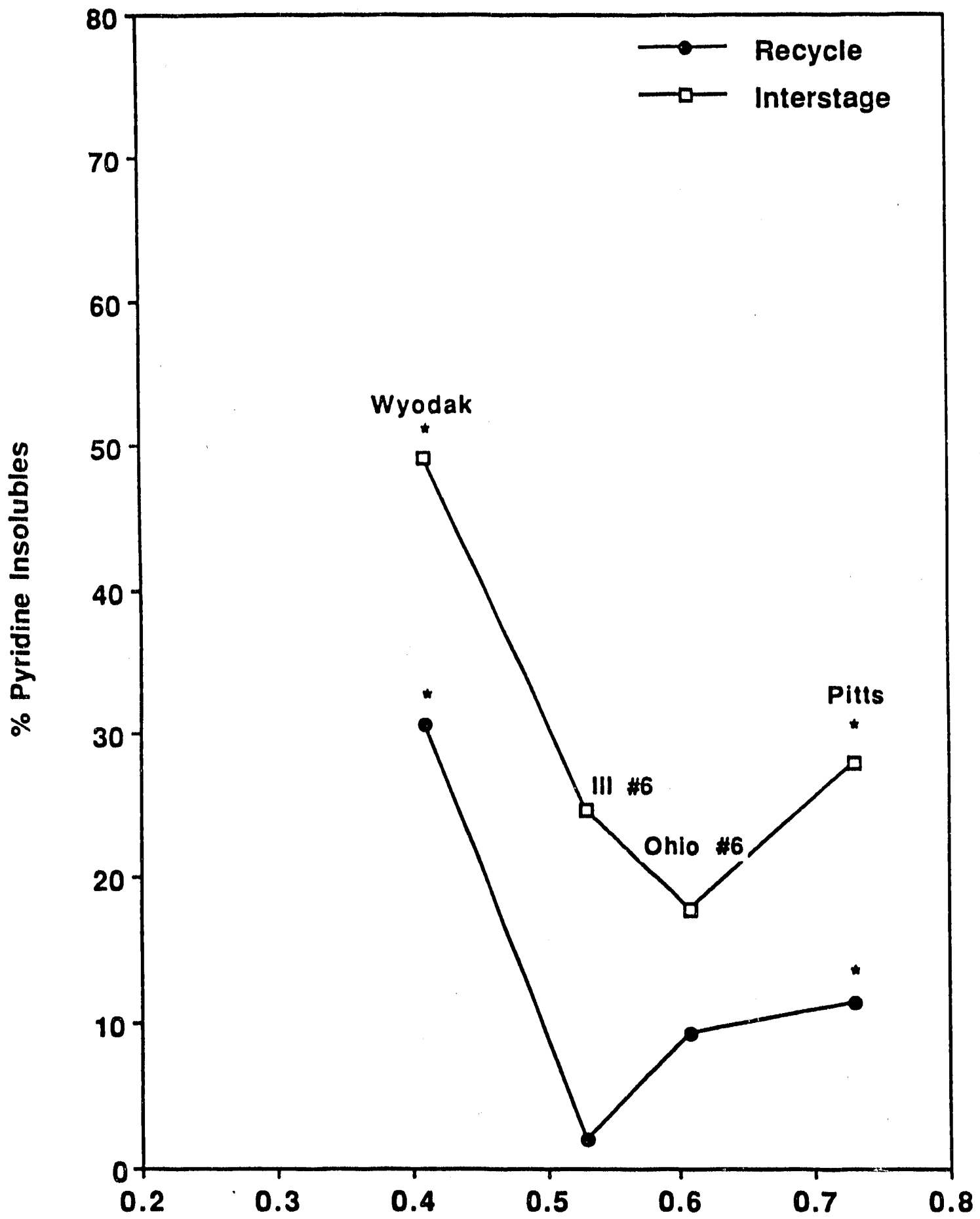

$\%$ Mean Max. Vitrinite Reflectance

Figure 5. Comparison of Interstage and Recycle Pyridine Insoluble with Vitrinite Reflectance (Rank) of Feed Coals

- Reflectance data for these coals obtained from Penn State Data Base. 


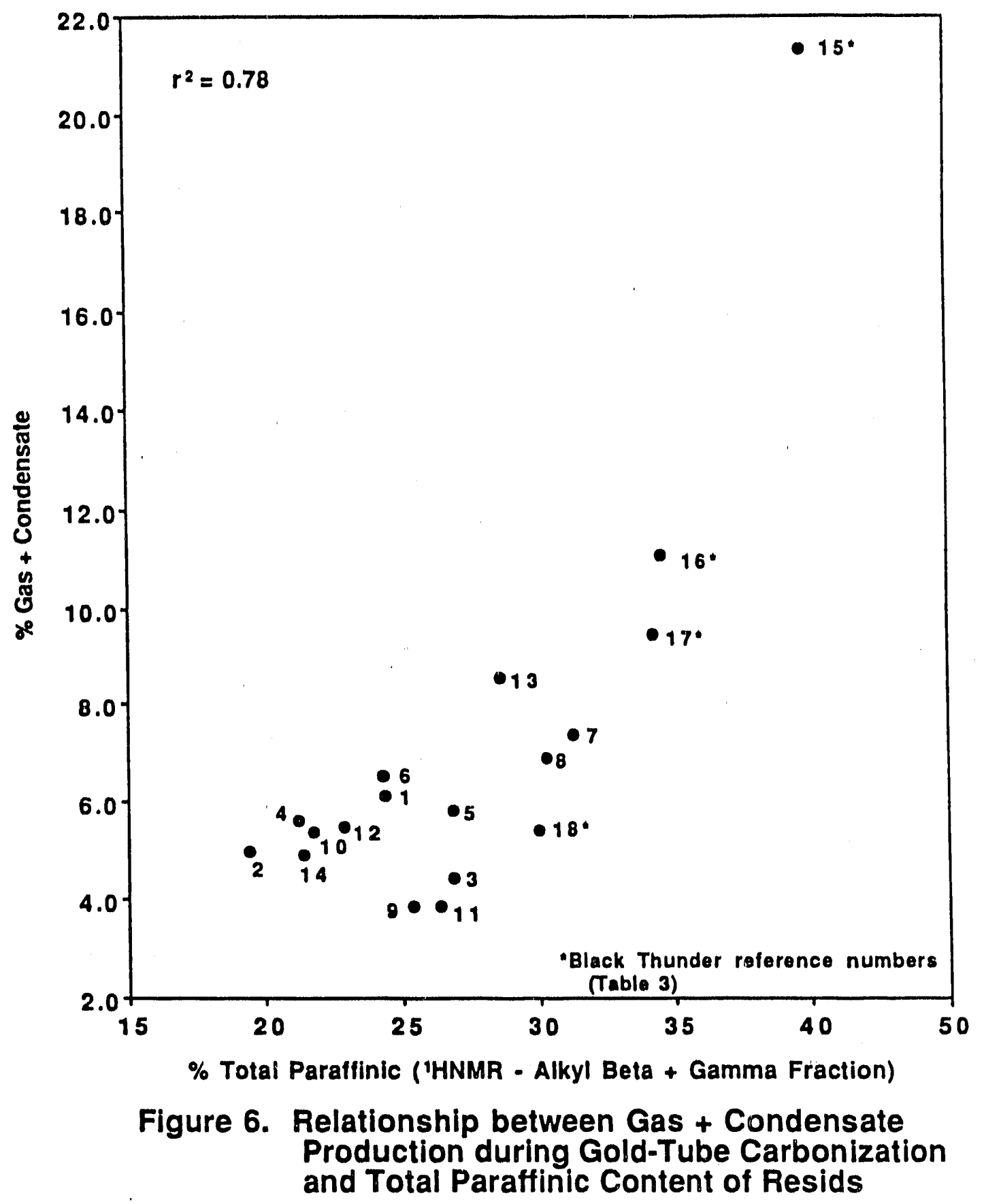




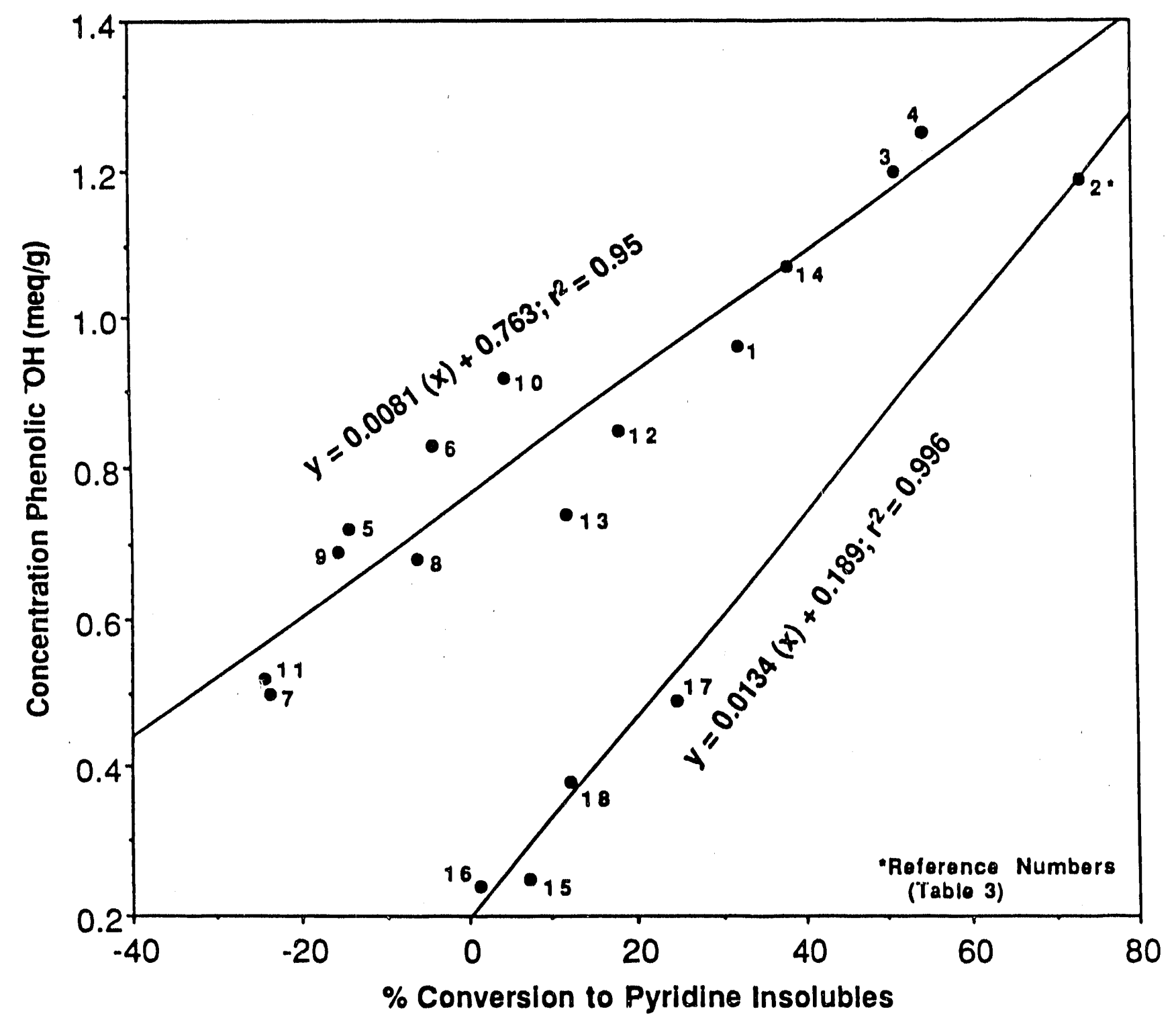

Figure 7. Relationship between Conversion to Pyridine Insolubles during Gold-Tube Carbonization and Concentration of Phenolic $\mathrm{OH}$ in Resids 


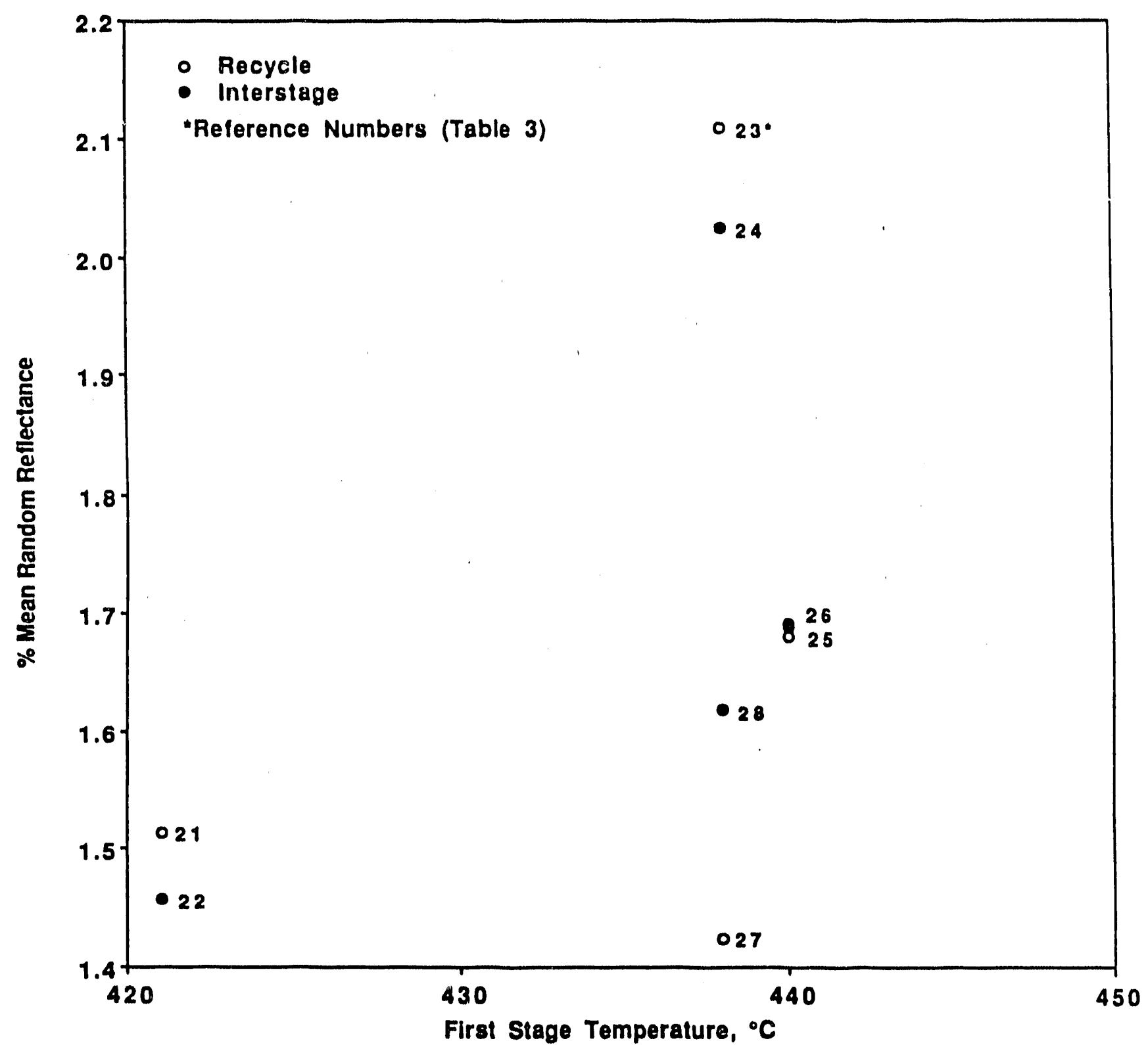

Figure 8. Vitroplast Reflectance from THF-Insoluble Residues as a Function of Process Stream and First-Stage Reaction Temperature 
a. The interrelationship between low-reflecting vitroplast (dark grey matrix) and spherical mesophase observed in pyridine-insoluble gold-tube carbonization residue of sample \#3 (Ohio \#6, Wilsonville run 256B resid).

b. Spherical mesophase formed in a matrix of coal- and process- derived IOM as found in the pyridine-insoluble gold-tube carbonization residue of sample $\# 7$ ( $111 \# 6$, Wilsonville run 257 resid). Most of the angular white and light-grey fragments are thought to have been formed from relatively unaltered coal fusinite and semifusinite.

c. The formation and partial coalescence of spherical mesophase found in the pyridine-insoluble gold-tube carbonization residue of sample \#13 (Ill\#6, Wilsonville run 250 resid).

d. Completely coalesced mesophase forming large anisotropic domains under partially crossed nicols in the same sample as " $c$ ". The molecular structure has undergone accommodation following coalescence. 


\section{PLATE II}

FIGURE DESCRIPTION

a. Relatively high-reflecting vitroplast particles (rounded) compared with coal-derived inertinite (angular) found in the THF-insoluble sample \#23 (Pittsburgh, Wilsonville run 259).

b. Partially reacted vitrinite (huminite) observed in the matrix (granular residue) of an agglomerate and found in the THF-insoluble sample \#26 (Wyodak, Wilsonville run 251-111).

c. Low-reflecting vitroplast serves as the matrix for ash and IOM as found in the whole-product sample \#8 (I11 \#6, Wilsonville run 257).

d. The central, low-reflecting spherically shaped particle is a remnant of low-reflecting vitroplast found in the THF-insoluble sample \#28 (I11\#6, Wilsonville run 250). 

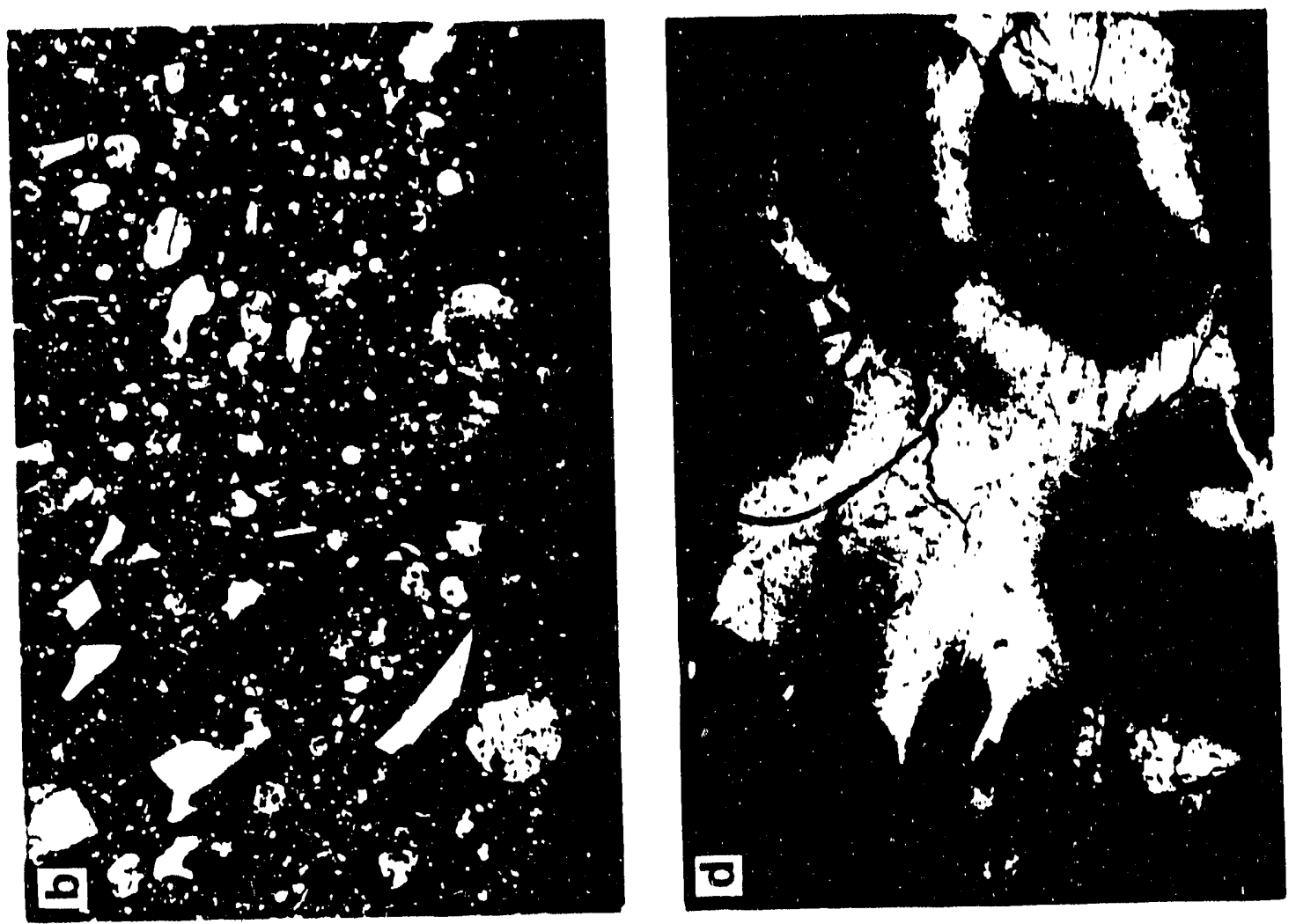

$\left.\begin{array}{l}E \\ \text { 요 }\end{array}\right]$
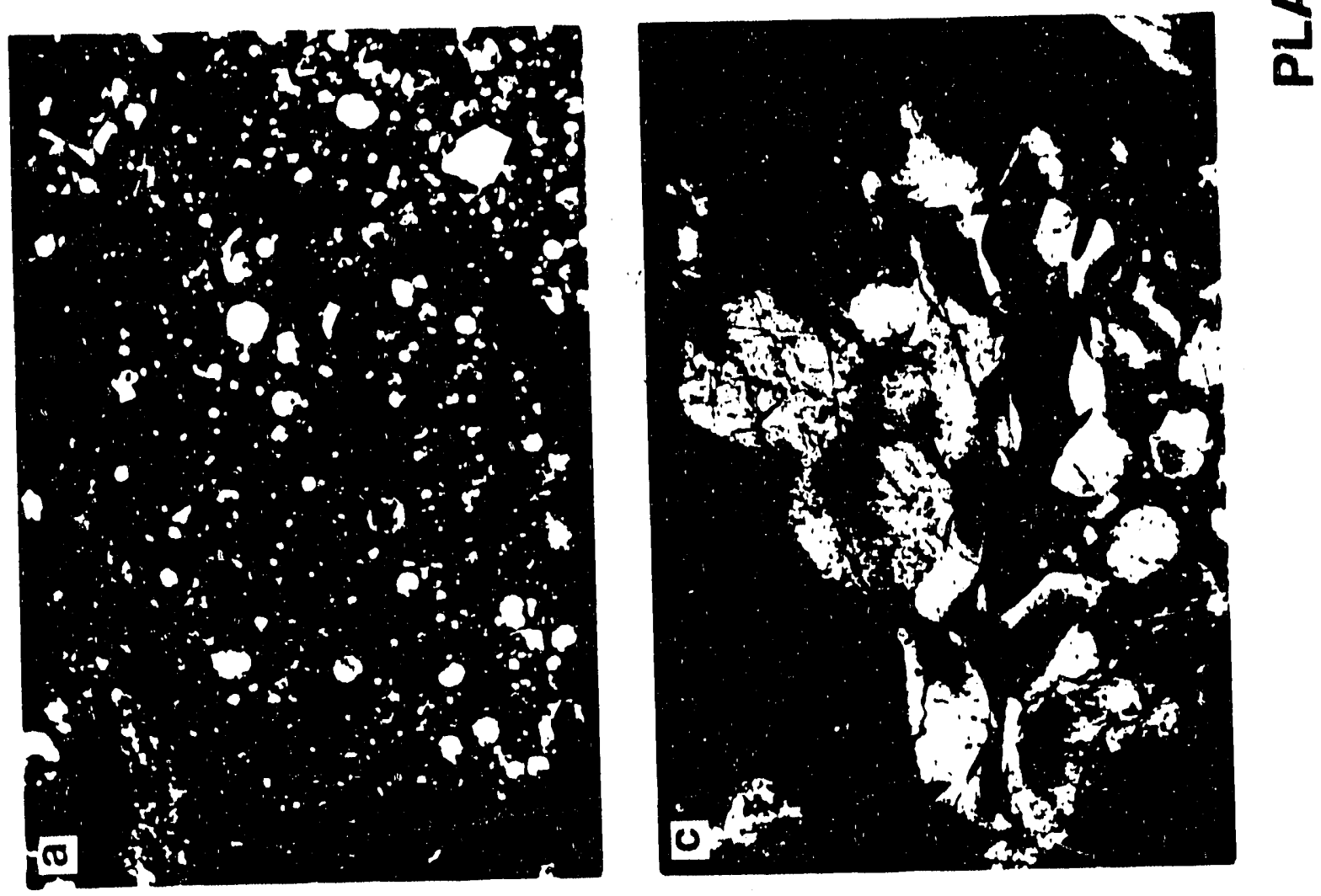

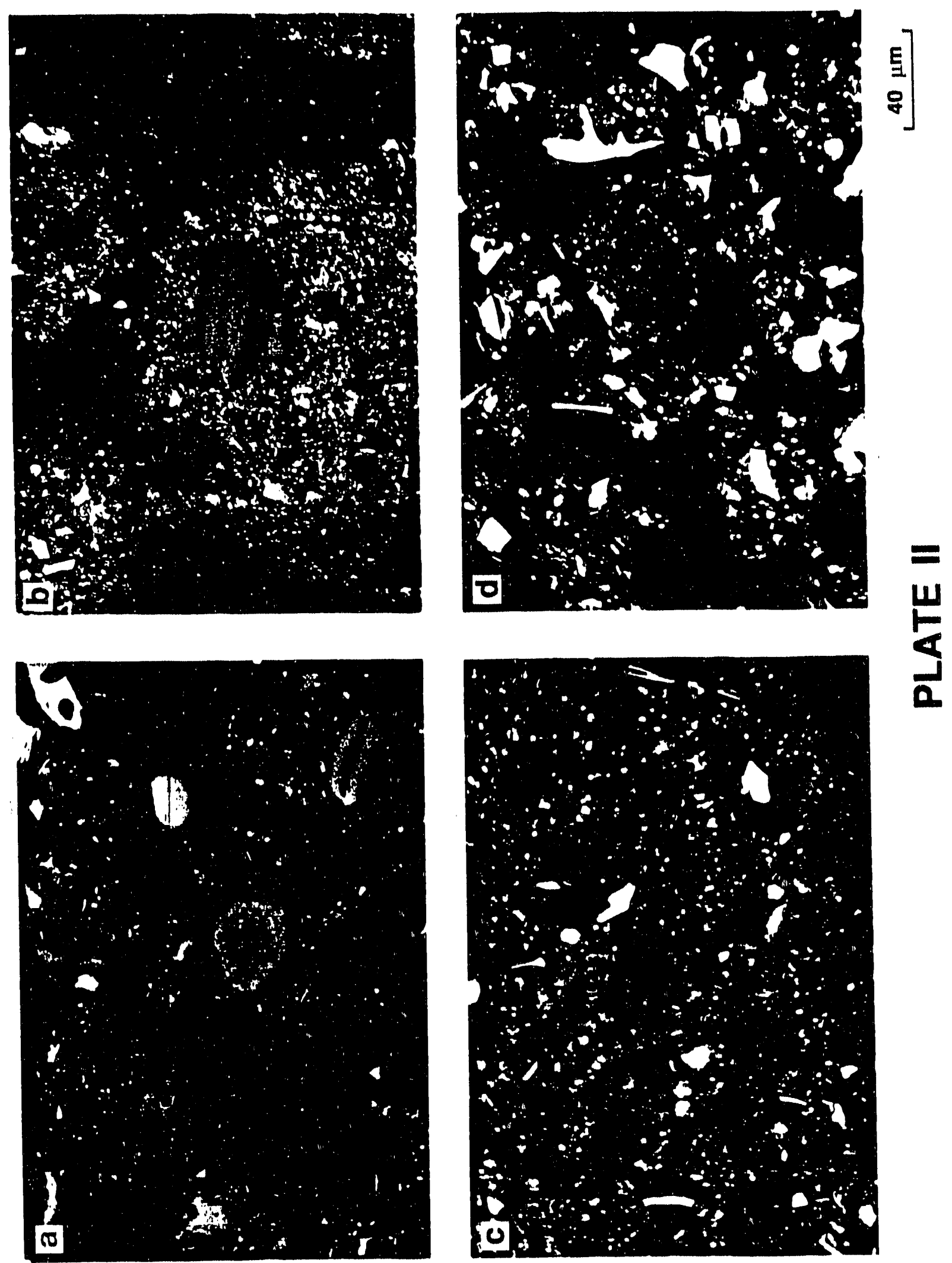

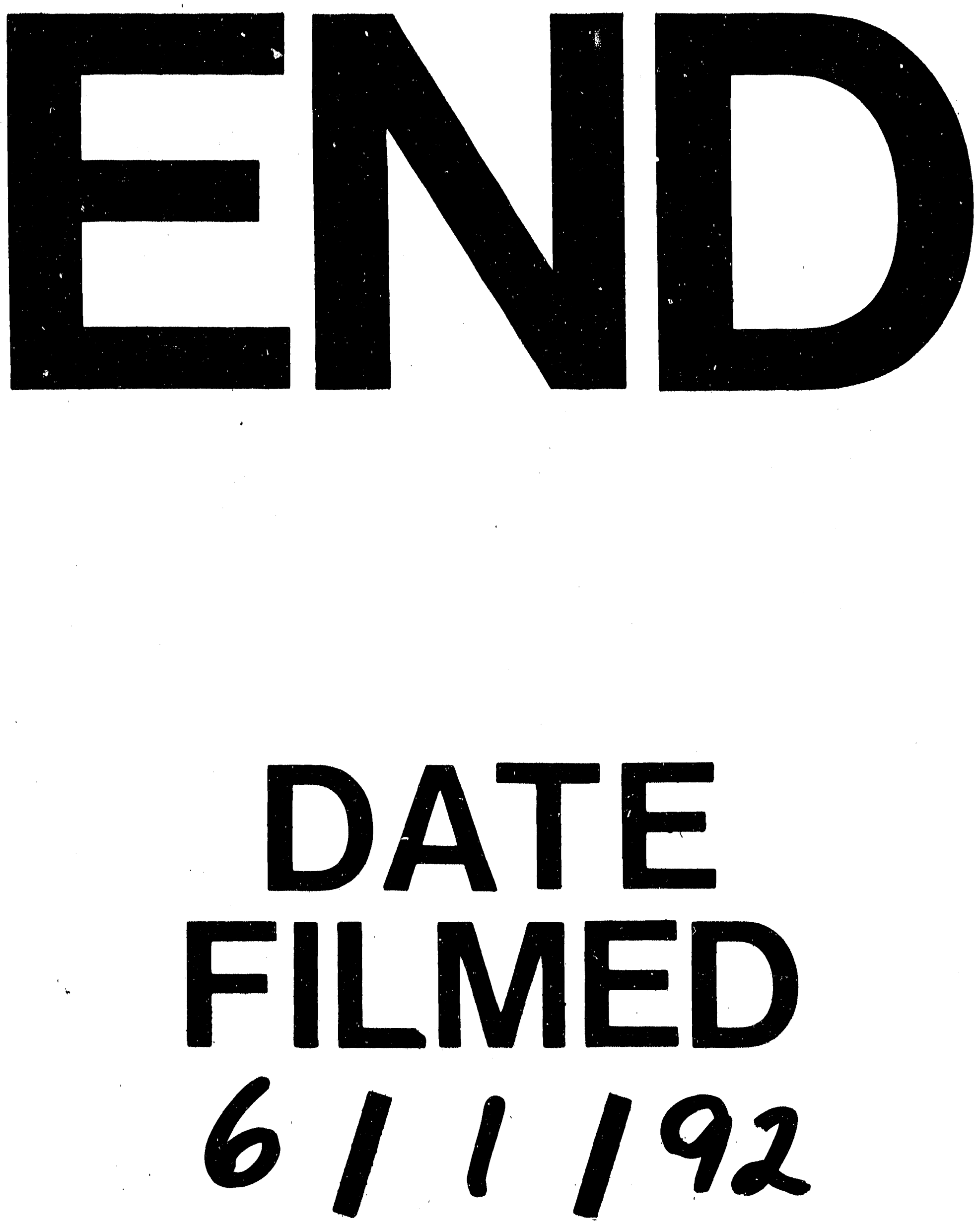
